\title{
A lab in the field: high-frequency analysis of water quality and stable isotopes in stream water and precipitation
}

\author{
Jana von Freyberg ${ }^{1,2}$, Bjørn Studer ${ }^{1}$, and James W. Kirchner ${ }^{1,2}$ \\ ${ }^{1}$ Department of Environmental Systems Science, ETH Zurich, Zurich, Switzerland \\ ${ }^{2}$ Swiss Federal Institute for Forest, Snow and Landscape Research (WSL), Birmensdorf, Switzerland \\ Correspondence to: Jana von Freyberg (jana.vonfreyberg@usys.ethz.ch)
}

Received: 10 November 2016 - Discussion started: 14 November 2016

Revised: 8 February 2017 - Accepted: 13 February 2017 - Published: 23 March 2017

\begin{abstract}
High-frequency measurements of solutes and isotopes $\left({ }^{18} \mathrm{O}\right.$ and $\left.{ }^{2} \mathrm{H}\right)$ in rainfall and streamflow can shed important light on catchment flow pathways and travel times, but the workload and sample storage artifacts involved in collecting, transporting, and analyzing thousands of bottled samples severely constrain catchment studies in which conventional sampling methods are employed. However, recent developments towards more compact and robust analyzers have now made it possible to measure chemistry and water isotopes in the field at sub-hourly frequencies over extended periods. Here, we present laboratory and field tests of a membrane-vaporization continuous water sampler coupled to a cavity ring-down spectrometer for real-time measurements of $\delta^{18} \mathrm{O}$ and $\delta^{2} \mathrm{H}$ combined with a dual-channel ion chromatograph (IC) for the synchronous analysis of major cations and anions. The precision of the isotope analyzer was typically better than $0.03 \%$ o for $\delta^{18} \mathrm{O}$ and $0.17 \%$ for $\delta^{2} \mathrm{H}$ in $10 \mathrm{~min}$ average readings taken at intervals of $30 \mathrm{~min}$. Carryover effects were less than $1.2 \%$ between isotopically contrasting water samples for 30 min sampling intervals, and instrument drift could be corrected through periodic analysis of secondary reference standards. The precision of the ion chromatograph was typically $\sim 0.1-1$ ppm or better, with relative standard deviations of $\sim 1 \%$ or better for most major ions in stream water, which is sufficient to detect subtle biogeochemical signals in catchment runoff.

We installed the coupled isotope analyzer/IC system in an uninsulated hut next to a stream of a small catchment and analyzed stream water and precipitation samples every $30 \mathrm{~min}$ over 28 days. These high-frequency measurements facilitated a detailed comparison of event-water fractions via endmember mixing analysis with both chemical and isotope tracers.
\end{abstract}

For two events with relatively dry antecedent moisture conditions, the event-water fractions were $<21 \%$ based on isotope tracers but were significantly overestimated (40 to $82 \%$ ) by the chemical tracers. These observations, coupled with the storm-to-storm patterns in precipitation isotope inputs and the associated stream water isotope response, led to a conceptual hypothesis for runoff generation in the catchment. Under this hypothesis, the pre-event water that is mobilized by precipitation events may, depending on antecedent moisture conditions, be significantly shallower, younger, and less mineralized than the deeper, older water that feeds baseflow and thus defines the "pre-event" endmember used in hydrograph separation. This proof-of-concept study illustrates the potential advantages of capturing isotopic and hydrochemical behavior at a high frequency over extended periods that span multiple hydrologic events.

\section{Introduction}

Environmental tracers are widely used in hydrology to investigate recharge processes, subsurface flow mechanisms, and streamflow components (Leibundgut and Seibert, 2011). The most common environmental tracers are the naturally occurring stable water isotopes ${ }^{18} \mathrm{O}$ and ${ }^{2} \mathrm{H}$ (Klaus and McDonnell, 2013). Solutes such as dissolved organic compounds, nutrients, and major ions are also widely used, together with stable isotopes, as indicators of flow paths and biogeochemical reactions (e.g., McGlynn and McDonnell, 2003; Vitvar and Balderer, 1997; Weiler et al., 1999). Environmental tracer studies typically involve manual or automated sample collection followed by transport, storage, and subsequent 
laboratory analysis. The time and effort involved in sample handling are often major constraints limiting the frequency and duration of sampling and thus the scope of tracer studies. While automated in situ analyzers for certain solutes and nutrients are becoming standard tools in environmental monitoring studies (e.g., Bende-Michl and Hairsine, 2010; Rode et al., 2016b), high-frequency analyses of isotopes and major ions over longer time periods remain challenging.

To date, isotope studies have maintained high sampling frequencies only during a few storm events (e.g., Berman et al., 2009; Lyon et al., 2008; Pangle et al., 2013) with the result that only limited ranges of catchment behavior have been explored. Long-term catchment studies capture a wider range of hydrologic events, but generally collect water samples at only weekly or monthly intervals for subsequent laboratory analysis (Buso et al., 2000; Darling and Bowes, 2016; Jasechko et al., 2016; Neal et al., 2011), making higherfrequency behavior unobservable. As pointed out by Kirchner et al. (2004), sampling at intervals much longer than the hydrological response times of a catchment may result in a significant loss of information. For instance, sub-daily sampling is required to capture diurnal fluctuations in stream water hydrochemistry, which reflect evapotranspiration effects or in-stream biological activity (e.g., Aubert and Breuer, 2016; Hayashi et al., 2012). In order to differentiate hydrological and biogeochemical catchment processes related to different water ages and flow pathways, long-term monitoring has to be complemented by additional high-frequency hydrochemical and isotope measurements. So far, only a few long-term studies have sampled stream water at daily or subdaily intervals for on-site measurements or subsequent analysis in the laboratory. These include studies conducted at Plynlimon in Wales (Neal et al., 2012), at the Kervidy-Naizin catchment in western France (Aubert et al., 2013), and at the Selke River in Germany (Rode et al., 2016a). Such studies have yielded fundamental insights into catchment hydrological behavior, not only at a wide range of temporal scales, but also under varying hydroclimatic conditions (Benettin et al., 2015; Halliday et al., 2013; Harman, 2015; Kirchner and Neal, 2013; Riml and Worman, 2015).

The recent development of compact and robust isotope analyzers has fostered initial attempts to continuously measure $\delta^{18} \mathrm{O}$ and $\delta^{2} \mathrm{H}$ in stream water or precipitation directly in the field. The only previous field-based isotope monitoring over 4 contiguous weeks was carried out by Berman et al. (2009) with a customized liquid water isotope analyzer based on offaxis integrated cavity output spectroscopy (OA-ICOS; Los Gatos Research, San Jose, CA, USA), which measured $\delta^{18} \mathrm{O}$ and $\delta^{2} \mathrm{H}$ in 90 samples per day. As the system was based on repeated injections of samples into a vaporizer, daily maintenance (i.e., injection septa change, filter cleaning) was required to keep it running. An alternative approach uses a semi-permeable membrane to generate water vapor from a continuous sample throughflow, which is then transferred to a wavelength-scanned cavity ring-down spectrometer (CRDS)
(Herbstritt et al., 2012). Munksgaard et al. (2011) developed such a custom-made diffusion sampler and attached it to a CRDS (Picarro Inc., Santa Clara, CA, USA) that was used to measure $\delta^{18} \mathrm{O}$ and $\delta^{2} \mathrm{H}$ in precipitation at frequencies of up to 30 s over a 15-day period (Munksgaard et al., 2012) as well as to monitor the isotopic response at $1 \mathrm{~min}$ resolution in streamflow during a storm event (Tweed et al., 2016).

A similar diffusion sampling system has recently become commercially available (Continuous Water Sampler, or CWS; Picarro Inc., Santa Clara, CA, USA), which allows for quasi-continuous measurements of $\delta^{18} \mathrm{O}$ and $\delta^{2} \mathrm{H}$ in liquid water samples when coupled to a CRDS analyzer. Here, we present initial laboratory and field verification experiments with this device, which we have combined with a dual-channel ion chromatograph (IC; Metrohm AG, Herisau, Switzerland) for real-time analysis of major cations and anions. Laboratory experiments quantifying the precision and sample carryover memory effects of this system are presented in Sect. 3. Section 4 illustrates the performance of the system in the field using a 28-day deployment at a small catchment in Switzerland. Section 5 quantifies the fractions of event water that contributed to the flood hydrograph in eight storm events, illustrating one potential application of high-frequency measurements of isotopes and major ions.

\section{Methodology}

\subsection{Isotope analysis and ion chromatography}

For the analysis of the stable water isotopes ${ }^{18} \mathrm{O}$ and ${ }^{2} \mathrm{H}$, the Continuous Water Sampler (CWS) was coupled to a wavelength-scanned cavity ring-down spectrometer (CRDS; model L2130-i; Picarro Inc., Santa Clara, CA, USA). In the CWS, the water sample flows at a rate of $\sim 1 \mathrm{~mL} \mathrm{~min}^{-1}$ through an expanded polytetrafluoroethylene (ePTFE) membrane tube. This tube is mounted in a stainless steel chamber that is supplied with dry air to facilitate the steady diffusion of a small fraction of the through-flowing water as vapor through the membrane. Through the continuous flow of dry air over the outer surface of the membrane, the vapor is carried directly to the CRDS for isotope analysis. To minimize temperature-induced fractionation effects, the instrument keeps the temperatures of the membrane chamber and the inflowing water constant at ( \pm 1 standard deviation) $45 \pm 0.1$ and $15 \pm 0.1{ }^{\circ} \mathrm{C}$, respectively. A solenoid diaphragm pump situated upstream of the membrane cartridge draws water samples from the sample container and pushes them through the membrane tube at a flow rate of approximately $1 \mathrm{~mL} \mathrm{~min}^{-1}$. As we show in Sect. 3.1, preliminary tests showed that this pump is not sufficient for our purposes, so we substituted a programmable high-precision dosing unit (800 Dosino, hereafter simply "Dosino"; Metrohm AG, Herisau, Switzerland) in its place. 


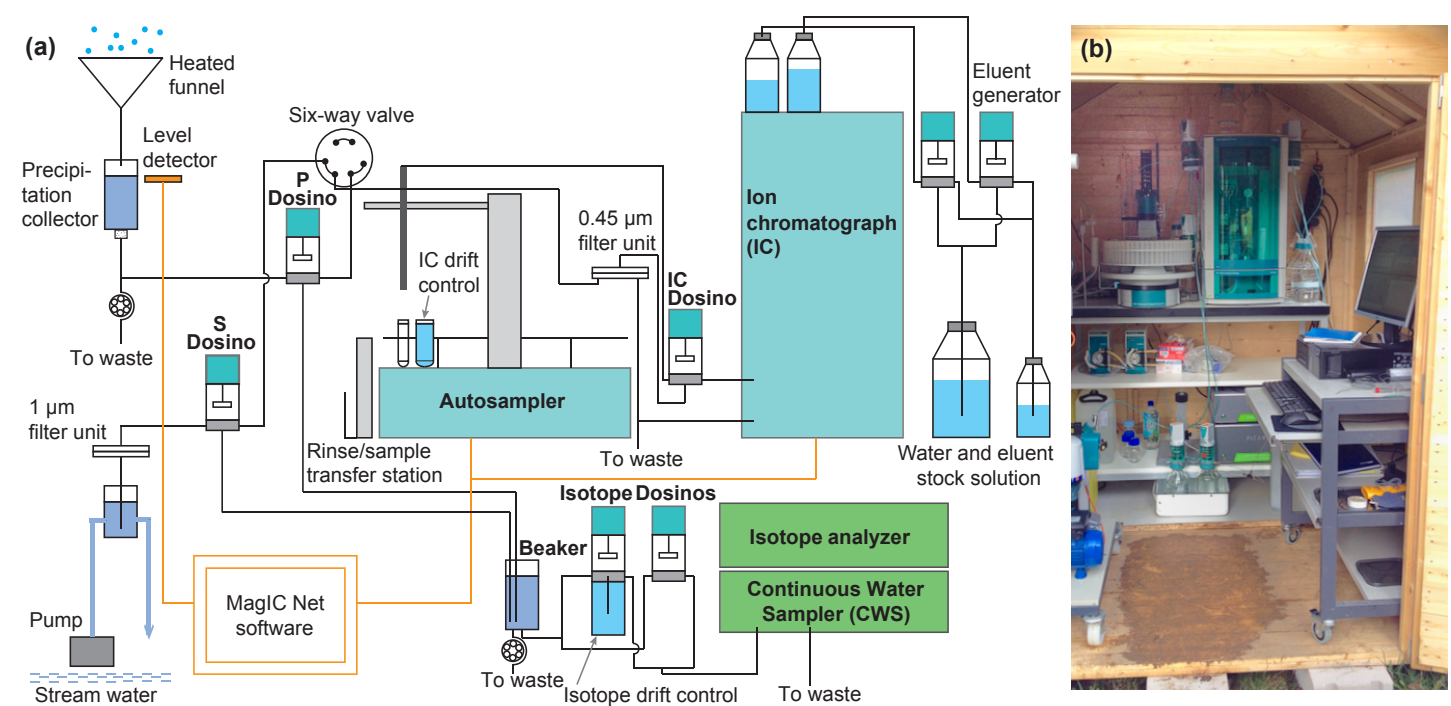

Figure 1. (a) Schematic overview of the coupled isotope analyzer/IC system for the collection and analysis of stream water and precipitation samples. The components of the sample distribution and the IC are shown in blue, while the isotope analyzer with the CWS is shown in green. Panel (b) shows a photo of the coupled isotope analyzer/IC system in the wooden hut during the field experiment.

Isotopic abundances are reported through the $\delta$ notation relative to the VSMOW-SLAP standards. For the laboratory experiments, we used the factory calibration of the isotope analysis system because only relative isotope values are needed for quantifying precision, drift, and carryover, and thus the absolute isotope values are unimportant. For the field experiment, however, we periodically measured two internal isotope standards (Fiji and Evian bottled water), which were calibrated by a Picarro L2130-i CRDS at the isotope laboratory of the University of Freiburg (Germany), to primary reference materials (IAEA standards SLAP, VSMOW, and GISP; instrument precision $0.16 \%$ for $\delta^{18} \mathrm{O}$ and $0.6 \%$ for $\left.\delta^{2} \mathrm{H}\right)$.

Major ions in liquid water samples, i.e., $\mathrm{Na}^{+}, \mathrm{K}^{+}, \mathrm{NH}_{4}^{+}$, $\mathrm{Ca}^{2+}, \mathrm{Mg}^{2+}, \mathrm{F}^{-}, \mathrm{Cl}^{-}, \mathrm{NO}_{3}^{-}, \mathrm{SO}_{4}^{2-}$, and $\mathrm{PO}_{4}^{3-}$, were analyzed with an ion chromatograph (940 Professional IC Vario, hereafter simply "IC"; Metrohm AG, Herisau, Switzerland) with a two-column configuration (anions, Metrosep A Supp 5-250/4.0; cations, Metrosep C6-250/4.0). Continuous operation of the instrument was possible due to fully automated eluent generation (941 Eluent Production Module; Metrohm AG, Herisau, Switzerland). To generate the full ion chromatograms of both anions and cations, approximately $28 \mathrm{~min}$ were required; thus, the sampling interval of the combined analysis system was fixed at $30 \mathrm{~min}$.

\subsection{Sample collection and distribution}

The water samples were distributed between the analyzers with high-precision dosing units (Dosinos). Each Dosino contains a programmable piston that fills and empties a glass cylinder with up to $50 \mathrm{~mL}$ of sample at a resolution of 10000 increments (implying $5 \mu \mathrm{L}$ increment $^{-1}$ ). The design of the dosing unit minimizes the dead volume and thus the potential for sample carryover. In the base of the glass cylinder sits a rotating valve disc that guides the liquid sample through one of four ports; thus, each Dosino functions as both a switching valve and a syringe pump.

Figure 1 depicts the schematic overview of the automatic sample collection and analysis system, showing how the different Dosinos distribute precipitation and stream water samples between the isotope analyzer, the IC, and an autosampler (which can be programmed to save individual samples for subsequent analysis in the laboratory). The sampling routine begins with a cleaning step during which either the P Dosino (which handles precipitation) or the S Dosino (which handles stream water) transports $10 \mathrm{~mL}$ of sample water for rinsing to a sample storage beaker. The Isotope Dosinos also eject any remaining sample into the beaker, after which the beaker is emptied. Then, $50 \mathrm{~mL}$ of fresh stream water or precipitation sample is transported (by either the S Dosino or the P Dosino for stream water or precipitation, respectively) into the rinsed beaker, from which one of the Isotope Dosinos draws $30 \mathrm{~mL}$ of water and injects it at a flow rate of $1 \mathrm{~mL} \mathrm{~min}^{-1}$ into the CWS for isotope analysis. The two Isotope Dosinos operate alternatingly to minimize the length of time that the sample flow into the CWS is interrupted. Meanwhile, either the $\mathrm{P}$ Dosino or the $\mathrm{S}$ Dosino takes up another $12 \mathrm{~mL}$ of water sample and pumps it through a $0.45 \mu \mathrm{m}$ tangential filter into the IC Dosino, which discards the first $2 \mathrm{~mL}$ of the filtered sample. From the remaining filtered sample, $8 \mathrm{~mL}$ are filled into vials by the autosampler and $2 \mathrm{~mL}$ are delivered to the IC for direct ion analysis. During the ion analysis (ca. $28 \mathrm{~min}$ ), the S Dosino, P Dosino, IC Dosino, the autosampler, and all 

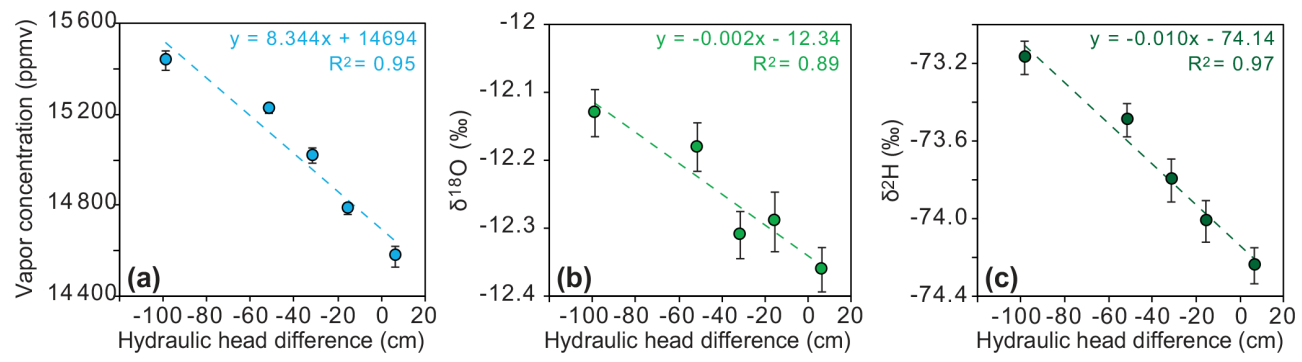

Figure 2. Laboratory experiment showing the isotope effects of sample injection into the Continuous Water Sampler (CWS). Panel (a) shows the measured vapor concentrations, and panels (b) and (c) show the raw, uncalibrated isotope values of a single water sample (nanopure water) as a function of the hydraulic head difference between the water level in the sample bottle and the waste outlet. Negative values of the hydraulic head difference indicate that the sample source was located below the waste outlet of the CWS.

tubing are rinsed with nanopure water to minimize carryover effects. The entire sampling routine is programmed with the IC control software MagIC Net (Metrohm, Herisau, Switzerland), which facilitates detailed data logging and documentation of the sample handling.

\section{Laboratory experiments}

\subsection{Optimization of sample injection into the Continuous Water Sampler (CWS)}

In the original design of the CWS, water samples are transported by a small solenoid diaphragm pump between the inlet port and the membrane cartridge at a flow rate of approximately $1 \mathrm{~mL} \mathrm{~min}{ }^{-1}$. During preliminary tests, however, we observed that raising or lowering the sample container detectably altered the reported isotope ratios. In order to quantify the sensitivity of the instrument to hydraulic head differences (i.e., the height of the water table in the sample bottle relative to the waste outlet of the CWS), we changed the elevation of the sample container relative to the instrument while continuously analyzing a single water sample (nanopure water). We measured the vapor concentration, $\delta^{18} \mathrm{O}$ and $\delta^{2} \mathrm{H}$ for the same water sample at five different elevations, ranging from $7 \mathrm{~cm}$ above to $98 \mathrm{~cm}$ below the waste outlet. The end of the waste outlet tube was always freely draining. Each configuration was measured for $1 \mathrm{~h}$, and the average values and standard deviations of the uncalibrated $6 \mathrm{~s}$ measurements of vapor concentration, $\delta^{18} \mathrm{O}$, and $\delta^{2}$ were calculated from the last $10 \mathrm{~min}$ of each $1 \mathrm{~h}$ configuration.

The results of this experiment are summarized in Fig. 2, which shows clear linear relationships between the hydraulic head differences and both the vapor concentrations and the isotope measurements. Lowering the sample source relative to the outflow results in systematically heavier isotopic values in the vapor measured by the instrument. The vapor concentrations show a similar trend; i.e., more vapor was generated at lower positions of the sample source. These observations suggest that the hydraulic head difference directly af- fected the flow rate of the liquid sample through the CWS membrane tube. Because the water is much colder than the surrounding air as it enters the membrane chamber, it is continuously warming as it travels through the membrane tube. At greater head gradients (and thus smaller flow rates), the sample will travel more slowly through the membrane chamber and will warm up more. At higher water temperatures, water should diffuse more rapidly through the membrane, and the resulting vapor will be less fractionated relative to the liquid phase (Kendall and McDonnell, 1998), as observed in Fig. 2.

It is unknown whether the empirical linear relationships shown in Fig. 2 are generally applicable or are specific to each individual membrane or to the properties of the sample. Nevertheless, for this membrane and this sample, the results indicate that changing the hydraulic head by $50 \mathrm{~cm}$ changes the reported isotope values by approximately $0.12 \%$ for $\delta^{18} \mathrm{O}$ and $0.52 \%$ o for $\delta^{2} \mathrm{H}$. This flow-rate artifact might become particularly important for applications in which isotope standards and samples are drawn from sample containers at different elevations relative to the waste outlet of the CWS (e.g., shipboard sampling). In such cases, a vapor concentration correction relative to a reference height would have to be carried out. Alternatively, a different injection system could be used to deliver a specified flow rate independent of the position of the source relative to the CWS. We used the 800 Dosino for this purpose, since it functions as a high-precision syringe pump with a delivery rate specified by the pulse rate of the stepper motor, independent of the hydraulic head gradient.

Because of the limited volume of each Dosino's glass cylinder $(50 \mathrm{~mL})$, a sample could be injected at a flow rate of $1 \mathrm{~mL} \mathrm{~min}{ }^{-1}$ for a maximum of $50 \mathrm{~min}$. For longer injections, or to switch samples, a second Dosino had to take over the sample delivery. The handoff between the Dosinos interrupted the sample flow to the CWS for around $2 \mathrm{~s}$. This interruption was reflected in a sharp but brief increase in vapor concentrations and isotope values, which returned back to stable values approximately $10 \mathrm{~min}$ after the injection started 


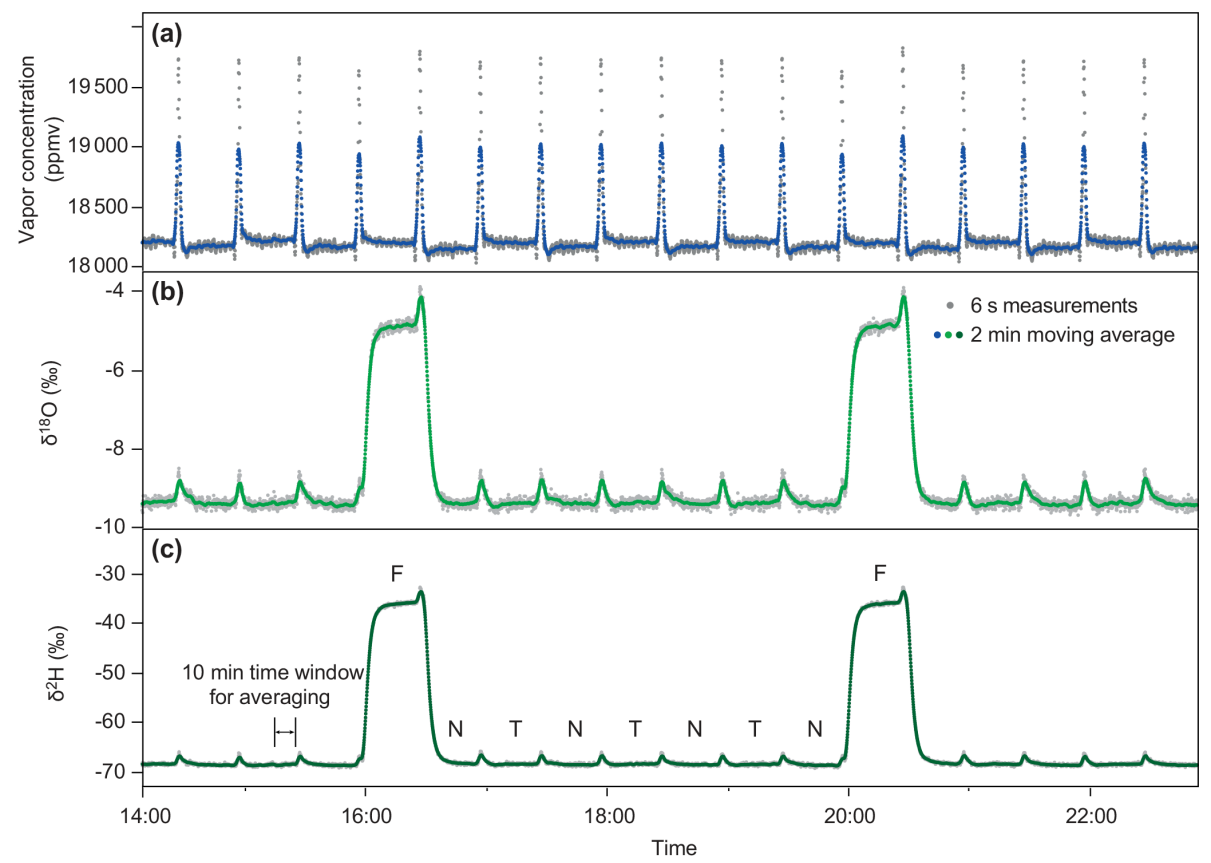

Figure 3. A $9 \mathrm{~h}$ excerpt showing the raw, uncalibrated data of vapor concentrations (panel a) and isotope measurements (panels b and c) in tap water $(\mathrm{T})$, nanopure water $(\mathrm{N})$, and Fiji bottled water $(\mathrm{F})$ during the $48 \mathrm{~h}$ laboratory experiment. The samples were injected alternately with two Dosinos for $30 \mathrm{~min}$ each at a flow rate of $1 \mathrm{~mL} \mathrm{~min}^{-1}$.

(see Fig. 3 for an example). For our application, i.e., synchronous IC measurements, we programmed a $30 \mathrm{~min}$ injection period for the isotope analysis. To obtain the final isotope values of a liquid sample, we averaged the individual $6 \mathrm{~s}$ measurements reported by the CRDS during the last $10 \mathrm{~min}$ of each $30 \mathrm{~min}$ injection period, using the first $20 \mathrm{~min}$ to minimize any memory effects from the previous sample or from Dosino changeover. The advantage of the Dosino-based sample handling system is the very steady, pressure-independent sample injection.

\subsection{Performance of the isotope analyzer with the Continuous Water Sampler (CWS)}

We quantified the precision, drift coefficients, and carryover effects of the isotope analyzer with the CWS and Dosinobased sample injection system using a continuous $48 \mathrm{~h}$ laboratory experiment that alternated between three water samples (i.e., to mimic stream water, precipitation, and a reference standard). The sample handling system was as shown in Fig. 1, except that the precipitation collector was replaced with a $10 \mathrm{~L}$ bottle of nanopure water and the stream water sampler was replaced by a $10 \mathrm{~L}$ bottle of tap water. The sampling system alternated between these two sources, and for each eighth injection it introduced an isotopically heavier secondary standard (Fiji bottled water) (Fig. 3). The isotopic differences between Fiji bottled water and tap water were about ( \pm standard error; SE) $4.54 \pm 0.02$ and $32.67 \pm 0.08 \%$ o for $\delta^{18} \mathrm{O}$ and $\delta^{2} \mathrm{H}$, respectively. The isotopic differences be- tween tap water and nanopure water were much smaller $\left(0.05 \pm 0.01 \%\right.$ of $\delta^{18} \mathrm{O}$ and $0.12 \pm 0.03 \%$ o for $\left.\delta^{2} \mathrm{H}\right)$ because the nanopure water was generated from the same tap water by reverse osmosis.

The precision of the isotope values, as quantified by the standard deviations of the individual $6 \mathrm{~s}$ measurements during the last $10 \mathrm{~min}$ of each injection period, was better than $0.08 \%$ or $\delta^{18} \mathrm{O}$ and $0.18 \%$ for $\delta^{2} \mathrm{H}$. These standard deviations imply that the standard errors of the 10 min averages should be better than 0.008 and $0.018 \%$ or $\delta^{18} \mathrm{O}$ and $\delta^{2} \mathrm{H}$, respectively. These standard errors overestimate the repeatability of successive measurements, however. As a measure of sample-to-sample repeatability, the standard deviations of the $10 \mathrm{~min}$ averages for the entire $48 \mathrm{~h}$ experiment were $0.03 \%$ o $\left(\delta^{18} \mathrm{O}\right)$ and $0.17 \% \circ\left(\delta^{2} \mathrm{H}\right)$ or better for each of the three water samples (excluding two outliers associated with an interruption in the sampling routine), much larger than the calculated standard errors. Thus, the major uncertainties in the 10 min averages do not arise from the counting statistics of the instrument itself, but rather, we suspect, from sample-tosample variability in the performance of the vaporizer. We use these larger estimates of uncertainty $\left(0.03 \%\right.$ for $\delta^{18} \mathrm{O}$ and $0.17 \%$ for $\delta^{2} \mathrm{H}$ ) in the error propagation calculations presented in Sect. 5.1.

Instrument drift was analyzed through linear regression of the $10 \mathrm{~min}$ averages from the ends of each $30 \mathrm{~min}$ injection period. The instrument drift for $\delta^{18} \mathrm{O}$ was statistically indistinguishable from zero for two of the three waters, averaging $( \pm \mathrm{SE})-0.009 \pm 0.008,-0.009 \pm 0.006$, and 
$-0.015 \pm 0.007 \%$ day $^{-1}$ for Fiji, nanopure, and tap water, respectively. The instrument drift for $\delta^{2} \mathrm{H}$ was slow but statistically significant for two of the three waters, averaging $0.133 \pm 0.040,0.084 \pm 0.016$, and $-0.021 \pm 0.021 \%$ o day $^{-1}$ for Fiji, nanopure, and tap water, respectively. Thus, the accumulated drift over 1 day was typically smaller than the measurement precision for individual $10 \mathrm{~min}$ averages for either isotope. As explained in Sect. 4.2, substantially faster drift occurred during the field experiment that could, however, easily be measured and corrected using regularly injected reference standards. This faster drift can be explained by biofilm growth on the membrane, which could be observed on the inside of the membrane tube during preliminary tests with stream water samples at the field site.

Between-sample memory mainly arises from small remnants of previously injected samples that remain in the sample handling system (e.g., tubes, membrane, valves, and pumps) or the analyzer itself, and are carried over to the following analysis. We quantified the between-sample memory effect of the isotope analyzer using two isotopically contrasting samples, Fiji water and nanopure water. The true isotopic difference was obtained from the seventh (and last) injection of nanopure water, which was measured around $3 \mathrm{~h}$ after the reference standard (Fiji) and was thus assumed to be free of any memory effects. We calculated the memory coefficient $(X)$ as a measure of carryover effects using Gupta et al. (2009):

$X=\frac{C_{i}-C_{i-1}}{C_{\text {true }}-C_{i-1}}$,

where $C$ denotes the isotope ratio (or the solute concentration), the indices $(i)$ and (i-l) denote the current and the previous injection, and (true) denotes the true value taken from the last value of multiple injections. Based on the $10 \mathrm{~min}$ averages from the end of each $30 \mathrm{~min}$ injection period, the average carryover from the Fiji bottled water to the next sample was $100 \% \cdot(1-X) \approx 0.9 \%$ for $\delta^{18} \mathrm{O}$ and $1.2 \%$ for $\delta^{2} \mathrm{H}$ (Table 1). The carryover during the first and second $10 \mathrm{~min}$ of each $30 \mathrm{~min}$ injection period was, however, much larger (up to 53 and $6 \%$, respectively), implying that our $30 \mathrm{~min}$ sampling cycle is indeed necessary to prevent unacceptably large carryover effects.

\subsection{Performance of the ion chromatograph (IC)}

With the IC, a $48 \mathrm{~h}$ laboratory experiment was carried out as well. However, the sampling sequence differed slightly from that of the isotope analyzer described previously: each measurement of tap water or Fiji water was followed by two to six samples of nanopure water, which mimics precipitation samples with generally very low solute concentrations. Due to the low solute concentrations in the nanopure water, the carryover effects can be quantified efficiently.

The average concentrations of the major anions and cations during the $48 \mathrm{~h}$ experiment are reported in Table 1 along with their absolute and relative standard deviations. For tap water and Fiji water, relative standard deviations were $<5 \%$ for all constituents with concentrations above the limit of quantification (LOQ) and $\sim 1 \%$ or less for most major ions, indicating that the IC measurements were stable over the $48 \mathrm{~h}$ period and that they were sufficiently precise to detect even subtle biogeochemical signals in stream water. The drift effects in the instrument were not statistically significant $(p>0.05)$ for most constituents in Fiji water and tap water. For $\mathrm{Cl}^{-}, \mathrm{NO}_{3}^{-}$, and $\mathrm{SO}_{4}^{2-}$ in the Fiji water, the linear drift was statistically significant but also very slow: the accumulated drift over $24 \mathrm{~h}$ was never much larger than the LOQ (Table 1). The average percent of carryover $(100 \% \cdot(1-X)$; Eq. 1) in the nanopure water sample, following immediately after a sample of tap water or Fiji water, was $\leq 3.8 \%$.

\section{Application in the field}

\subsection{Setup}

For the field experiment, the system was installed in a hut (area $1.7 \mathrm{~m} \times 1.7 \mathrm{~m}$ ) next to a small perennial stream flowing behind the Swiss Federal Institute for Forest, Snow and Landscape Research (WSL) near Zurich, Switzerland. The creek drains an area mainly covered with open grassland, grain fields, and suburban residential neighborhoods (Fig. 4). The dominant soil type is colluvial, partly gleyic brown soil (GIS-ZH, 2016).

The hut was connected to the electricity grid to allow for the continuous operation of all instruments. Stream stage, temperature and electrical conductivity were recorded in the stream every $10 \mathrm{~min}$ using a data logging sonde (model DL/N70; STS Sensor Technik Sirnach AG, Sirnach, Switzerland). The volumetric discharge was not gauged, but we assume that the times of the highest stream stage coincided with peak flow, and thus we use both terms synonymously. Once a day at 07:30, daily precipitation was measured with a heated collector and snow depth was recorded. For higher temporal resolution, we used the hourly CombiPrecip data set (MeteoSwiss), a grid-data product that combines radar estimates and rain gauge measurements to compute precipitation rates at $1 \mathrm{~km}^{2}$ spatial resolution. Good agreement $\left(R^{2}=0.86\right)$ between the measured daily precipitation at our field site and the daily sums of hourly CombiPrecip data indicate that the CombiPrecip data set is a reasonable proxy for precipitation variability at the field site. To distinguish rain and snowfall events, air temperature was recorded near the instrument hut every $10 \mathrm{~min}$ (Haeni, 2016; Schaub et al., 2011). The uninsulated hut was not temperature controlled; however, the instruments produced heat so that inside air temperatures were on average $12^{\circ} \mathrm{C}$ higher than outside. Outside air temperature variations were reflected inside the hut, where air temperatures ranged from 7 to $23^{\circ} \mathrm{C}$. 
Table 1. Average isotope values and solute concentrations as well as standard deviations (and relative standard deviations; RSDs) of three water samples analyzed during two different $48 \mathrm{~h}$ laboratory experiments with the isotope analyzer and the IC, respectively. In Fiji bottled water, tap water, and nanopure water, concentrations of $\mathrm{F}^{-}, \mathrm{Li}^{+}, \mathrm{K}^{+}, \mathrm{NH}_{4}^{+}$, and $\mathrm{PO}_{4}^{3-}$ were mostly below the limit of quantification (LOQ) and thus were not included in the table. The calculation of the average memory coefficient is described in the text (Eq. 1). The uncertainties in the IC measurements were obtained by simple linear regression analysis of the average value and the standard deviation of the respective constituent.

\begin{tabular}{|c|c|c|c|c|c|c|c|c|}
\hline & \multicolumn{2}{|c|}{$\begin{array}{c}\text { Isotope analyzer } \\
48 \mathrm{~h} \text { laboratory } \\
\text { experiment }\end{array}$} & \multicolumn{6}{|c|}{ IC $48 \mathrm{~h}$ laboratory experiment } \\
\hline & $\begin{array}{r}\delta^{18} \mathrm{O} \\
(\% \circ)\end{array}$ & $\begin{array}{l}\delta^{2} \mathrm{H} \\
(\% o)\end{array}$ & $\begin{array}{r}\mathrm{Na}^{+} \\
\left(\mathrm{mg} \mathrm{L}^{-1}\right)\end{array}$ & $\begin{array}{r}\mathrm{Mg}^{2+} \\
\left(\mathrm{mg} \mathrm{L}^{-1}\right)\end{array}$ & $\begin{array}{r}\mathrm{Ca}^{2+} \\
\left(\mathrm{mg} \mathrm{L}^{-1}\right)\end{array}$ & $\begin{array}{r}\mathrm{Cl}^{-} \\
\left(\mathrm{mg} \mathrm{L}^{-1}\right)\end{array}$ & $\begin{array}{r}\mathrm{NO}_{3}^{-} \\
\left(\mathrm{mg} \mathrm{L}^{-1}\right)\end{array}$ & $\begin{array}{r}\mathrm{SO}_{4}^{2-} \\
\left(\mathrm{mg} \mathrm{L}^{-1}\right)\end{array}$ \\
\hline Limit of quantification (LOQ) & - & - & 0.1 & 0.1 & 0.1 & 0.05 & 0.05 & 0.05 \\
\hline Measurement uncertainty & 0.03 & 0.17 & $\begin{array}{r}0.053+ \\
0.005 \cdot C\end{array}$ & $\begin{array}{r}0.008+ \\
0.006 \cdot C\end{array}$ & $\begin{array}{r}0.087+ \\
0.009 \cdot C\end{array}$ & $\begin{array}{r}0.027+ \\
0.003 \cdot C\end{array}$ & $\begin{array}{r}0.028+ \\
0.002 \cdot C\end{array}$ & $\begin{array}{r}0.037+ \\
0.006 \cdot C\end{array}$ \\
\hline Water sample & \multicolumn{2}{|c|}{ Fiji bottled water } & \multicolumn{6}{|c|}{ Fiji bottled water } \\
\hline Number of measurements & 12 & 12 & 10 & 10 & 10 & 10 & 10 & 10 \\
\hline Average value & -4.86 & -35.89 & 21.6 & 15.7 & 24.3 & 9.69 & 1.05 & 1.56 \\
\hline Standard deviation & 0.06 & 0.26 & 0.1 & 0.1 & 0.3 & 0.06 & 0.05 & 0.03 \\
\hline RSD & - & - & $0.5 \%$ & $0.4 \%$ & $1.1 \%$ & $0.60 \%$ & $4.3 \%$ & $1.80 \%$ \\
\hline $\begin{array}{l}\text { Linear drift per } 24 \mathrm{~h} \\
\text { (mean } \pm \text { standard error) }\end{array}$ & $\begin{array}{r}-0.009 \pm \\
0.008\end{array}$ & $\begin{array}{r}0.133 \pm \\
0.040\end{array}$ & $\begin{array}{r}0.129 \pm \\
0.056^{\mathrm{a}}\end{array}$ & $\begin{array}{r}0.058 \pm \\
0.036^{\mathrm{b}}\end{array}$ & $\begin{array}{r}0.093 \pm \\
0.160^{\mathrm{c}}\end{array}$ & $\begin{array}{r}0.088 \pm \\
0.019\end{array}$ & $\begin{array}{r}-0.078 \pm \\
0.008\end{array}$ & $\begin{array}{r}0.045 \pm \\
0.007\end{array}$ \\
\hline Water sample & \multicolumn{2}{|c|}{ Tap water } & \multicolumn{6}{|c|}{ Tap water } \\
\hline Number of measurements & 34 & 34 & 18 & 18 & 18 & 18 & 18 & 18 \\
\hline Average value & -9.40 & -68.55 & 10.9 & 34.4 & 133.2 & 12.41 & 4.96 & 17.29 \\
\hline Standard deviation & 0.03 & 0.12 & 0.2 & 0.2 & 1.3 & 0.057 & 0.03 & 0.14 \\
\hline RSD & - & - & $1.6 \%$ & $0.6 \%$ & $1.0 \%$ & $0.5 \%$ & $0.7 \%$ & $0.8 \%$ \\
\hline Water sample & \multicolumn{2}{|c|}{ Nanopure water } & \multicolumn{6}{|c|}{ Nanopure water (last sample) } \\
\hline Number of measurements & 43 & 43 & 27 & 27 & 27 & 27 & 27 & 27 \\
\hline Average value & -9.44 & -68.67 & $<\mathrm{LOQ}$ & 0.1 & 0.6 & $<\mathrm{LOQ}$ & $<$ LOQ & 0.09 \\
\hline Standard deviation & 0.02 & 0.18 & 0.02 & 0.003 & 0.1 & 0.03 & 0.02 & 0.05 \\
\hline Carryover & $0.9 \%$ & $1.2 \%$ & $2.8 \%$ & $3.3 \%$ & $3.8 \%$ & $2.1 \%$ & $1.9 \%$ & $2.3 \%$ \\
\hline
\end{tabular}

${ }^{\mathrm{a}} p>0.05 .{ }^{\mathrm{b}} p>0.15 .{ }^{\mathrm{c}} p>0.50$.

A submersible pump (EHEIM GmbH \& Co KG, Deizisau, Germany) continuously pumped stream water at a rate of $6 \mathrm{~L} \mathrm{~min}^{-1}$ into a throughflow bucket inside the hut. The volume of the bucket was $10 \mathrm{~L}$; thus, every several minutes the contents of the bucket were effectively exchanged. Every $30 \mathrm{~min}$, water was drawn from the bucket by the S Dosino through a $1 \mu \mathrm{m}$ cellulose filter to supply the isotope analyzer, IC, and autosampler (Fig. 1). Precipitation was collected with a heated $45 \mathrm{~cm}$ diameter funnel installed $2.5 \mathrm{~m}$ above the ground. Precipitation flowed into a Teflon ${ }^{\circledR}$-coated collector with a level detector. The status of the level detector was queried before the end of each measurement routine, and a precipitation sample was taken only if the threshold volume of $72 \mathrm{~mL}$ (equaling roughly $0.5 \mathrm{~mm}$ of precipitation) was exceeded. For the initial filtration of the precipitation sample, a ceramic frit filter was attached to the suction tube of the $\mathrm{P}$ Dosino that drew the sample from the precipitation collector. After precipitation was sampled, a peristaltic pump emptied the precipitation collector to avoid mixing fresh and old precipitation samples. The sampling routine was programmed to always alternate between stream water and precipitation samples in order to obtain enough stream water samples during storm periods. To reduce biofilm growth on the membrane in the CWS, copper wool was placed in the beaker from which the Isotope Dosinos drew the samples. Sampling was interrupted approximately once a week for basic maintenance (i.e., replacing the filter membranes, cleaning the Dosinos, and refilling the reference standards and eluent stock solutions).

To correct for instrument drift, internal reference standards were analyzed every $3 \mathrm{~h}$. For the five samples between two bracketing measurements of the same reference standard, the following equation was applied:

$C_{\text {corr }}=C_{\text {raw }}+\left(C_{\text {true }}-\frac{C_{\text {std }, i}+C_{\text {std }, j}}{2}\right)$, 


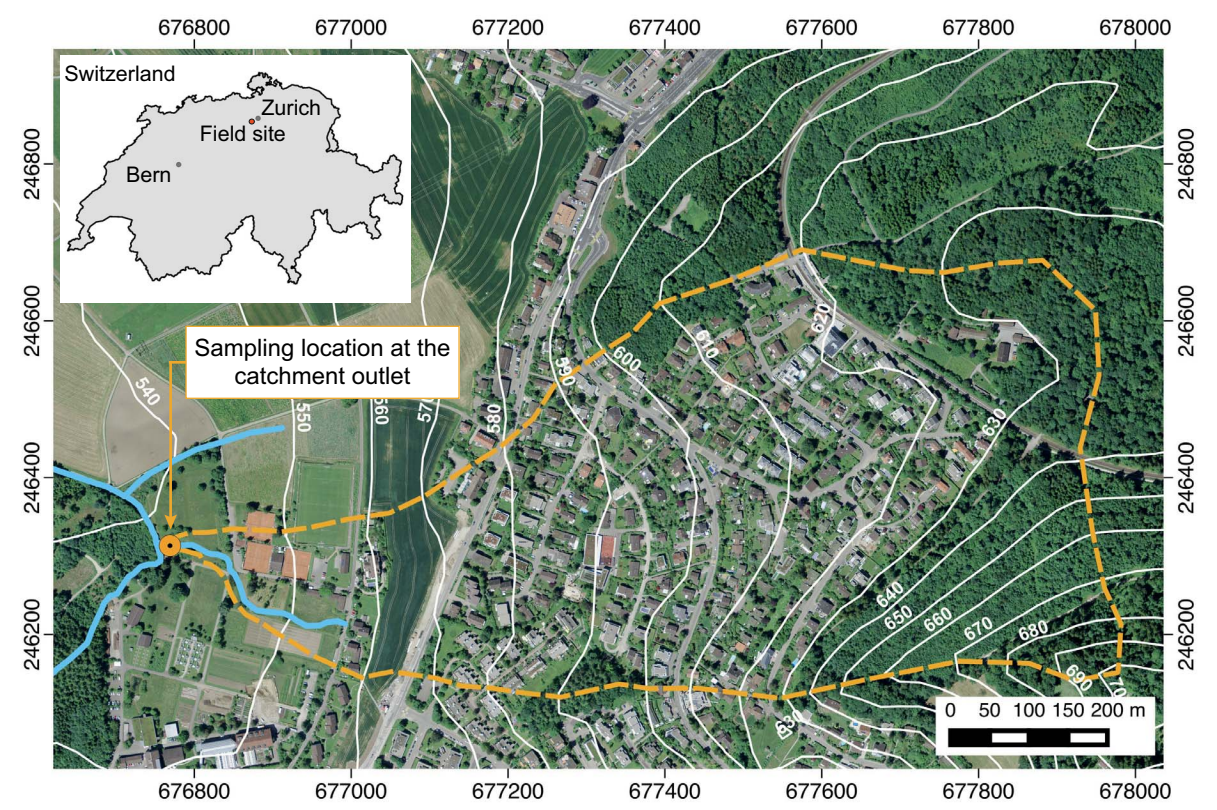

Figure 4. Location of the field site at a small creek on the property of the Swiss Federal Institute for Forest, Snow and Landscape Research (WSL) near Zurich, Switzerland. The catchment boundaries are approximate.

with $C$ denoting the solute concentration or the isotope ratio, respectively. The indices represent the corrected value (corr), the current raw measurement (raw), the true value of the reference standard (true), and the previous and successive measurements of the same reference standard (std) measured at time $i$ and $3 \mathrm{~h}$ later at time $j$. For the isotope analyzer, Fiji bottled water was used as an internal reference standard, which was injected directly from a container by one of the Isotope Dosinos (Fig. 1). The measurements of the IC were drift-corrected with another reference standard (Evian bottled water) that was transferred directly to the IC by the IC Dosino. Evian bottled water was used, as its mineral composition resembles that of stream water more closely than Fiji bottled water does.

\subsection{Temporal high-resolution measurements of stable isotopes and major ions in precipitation and stream water}

The measurement system was deployed at the field site from 13 February 2016 to 11 March 2016, and more than 1000 stream water and precipitation samples were analyzed for stable water isotopes and major ions, capturing a wide range of hydrological and hydrochemical conditions. Table 2 provides an overview of the eight storm events during that period. Air temperature measurements at the site and daily observations of the snow height showed that precipitation during Events 1-7 was mostly rainfall. Snowfall occurred occasionally after 1 March, while during Event 8 most precipitation fell as snow.
We calculated the response time of streamflow as the time difference between the first detection of precipitation and the first significant increase in stream water level relative to the initial conditions. The response times were between 0 and $2.5 \mathrm{~h}$ (Table 2), suggesting fast runoff from the residential area in the eastern part of the catchment. The most delayed streamflow response $(2.5 \mathrm{~h})$ was observed after the snowfall Event 8, reflecting delayed snowmelt. As illustrated by Fig. 5, a 30 min sampling interval was sufficient to resolve the temporal patterns of stable isotopes and solutes in streamflow during the rising limb of the hydrograph, even during low-intensity precipitation periods such as Event 5 .

Compared to the laboratory experiment with the isotope analyzer, during the field experiment we observed carryover effects in the isotope measurements of up to $100 \% \cdot(1-$ $X)=3 \%$, which can be explained by the copper wool in the beaker from which the Isotope Dosinos drew the water samples. Despite the rinsing routine of the beaker, the wool retained small volumes of sample from previous injections that affected the isotopic composition in the fresh sample. Consequently, the wool was removed and the prior isotope measurements were adjusted with $X=97 \%$ and Eq. (1). Further, the instrument drift was substantially faster at the beginning of the field experiment due to biofilm growth in the membrane tube. For instance, during the first week, the instrument drift for raw $\delta^{18} \mathrm{O}$ and $\delta^{2} \mathrm{H}$ measurements in the Fiji bottled water was statistically significant, averaging $( \pm \mathrm{SE})$ $-0.185 \pm 0.006$ and $-0.288 \pm 0.015 \%$ o day ${ }^{-1}$, respectively. The variations in air temperature outside and inside the hut were not reflected in the isotope measurements because the 
Table 2. Characteristics of precipitation events and antecedent moisture conditions during the field experiment. The initial stream stage is used here as a proxy for the initial discharge.

\begin{tabular}{|c|c|c|c|c|c|c|c|}
\hline Event & Start of event & $\begin{array}{r}\text { Total } \\
\text { precipitation } \\
(\mathrm{mm})\end{array}$ & $\begin{array}{r}\text { Total } \\
\text { precipitation } \\
\text { until peak } \\
\text { flow }(\mathrm{mm})\end{array}$ & $\begin{array}{r}\text { Response } \\
\text { time } \\
(\mathrm{h}: \mathrm{min})\end{array}$ & $\begin{array}{r}48 \mathrm{~h} \\
\text { antecedent } \\
\text { precipitation } \\
(\mathrm{mm})\end{array}$ & $\begin{array}{r}24 \mathrm{~h} \text { antecedent } \\
\text { precipitation } \\
(\mathrm{mm})\end{array}$ & $\begin{array}{r}\text { Initial } \\
\text { stream stage } \\
(\mathrm{m})\end{array}$ \\
\hline 1 & 14 February 2016 11:00 & 5.8 & 2.2 & 01:10 & 8.3 & 2.7 & 0.44 \\
\hline 2 & 20 February 2016 10:00 & 11.5 & 8.8 & $00: 30$ & 1.9 & 0.5 & 0.36 \\
\hline 3 & 23 February 2016 08:00 & 5.8 & 3.5 & 00:00 & 0.8 & 0.8 & 0.37 \\
\hline 4 & 24 February 2016 15:00 & 14.3 & 8.1 & 01:00 & 6.6 & 5.0 & 0.41 \\
\hline 5 & 29 February 2016 13:00 & 10.5 & 2.0 & 00:00 & 0.0 & 0.0 & 0.38 \\
\hline 6 & 2 March 2016 13:00 & 8.7 & 6.8 & 01:10 & 12.3 & 1.9 & 0.46 \\
\hline 7 & 5 March 2016 04:00 & 11.5 & 9.4 & $02: 10$ & 4.6 & 0.9 & 0.45 \\
\hline 8 & 7 March 2016 23:00 & 8.4 & 8.4 & $02: 30$ & 0.6 & 0.0 & 0.45 \\
\hline
\end{tabular}

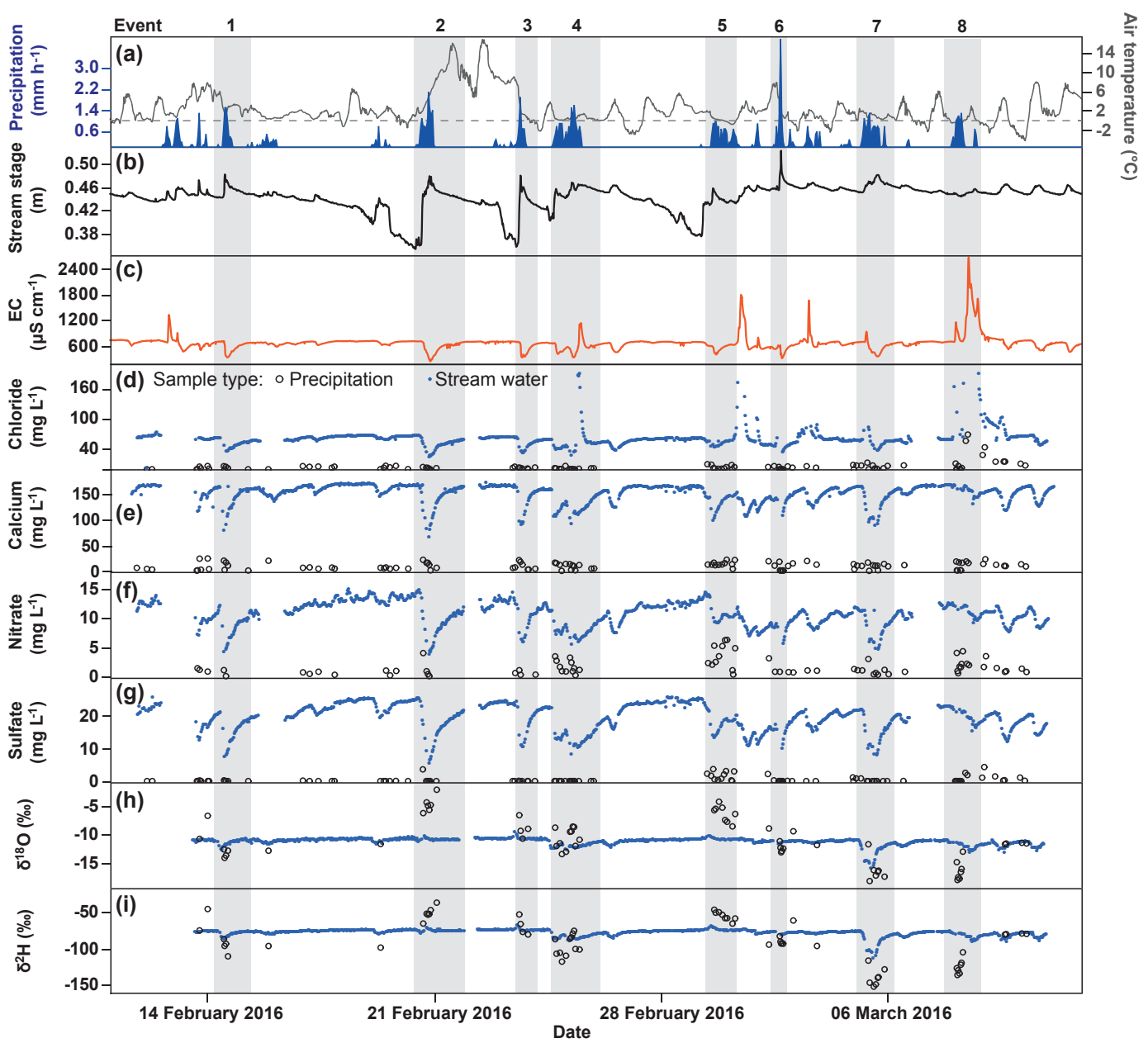

Figure 5. Time series of (a) precipitation and air temperature as well as (b) stream stage at the field site during the 4-week study period. Panel (c) shows stream water EC, whereas panels (d-g) show the chloride, calcium, nitrate, and sulfate concentrations, respectively. Panels (h) and (i) show the isotopic compositions of precipitation and stream water samples. The stream water samples are shown by the blue dots, and the precipitation samples are shown by the open circles. The vertical grey bars indicate the periods of the eight precipitation events used for hydrograph separation. 

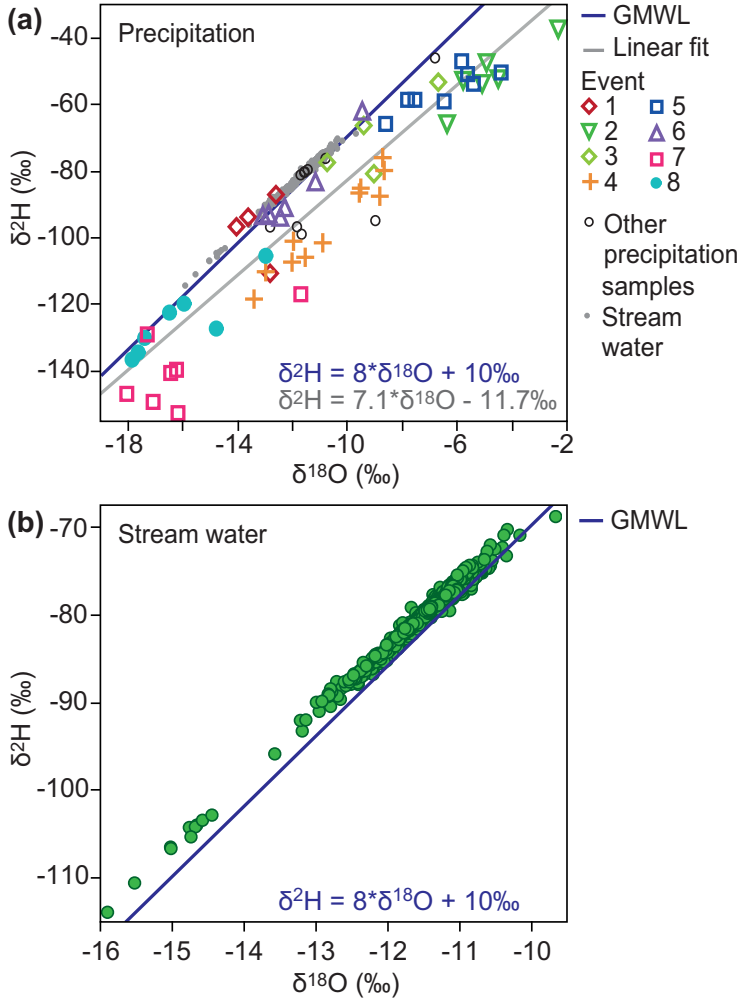

Figure 6. Dual-isotope plot of all $\delta^{18} \mathrm{O}$ and $\delta^{2} \mathrm{H}$ values measured in (a) precipitation and (b) stream water during the field experiment. The stream water samples are also plotted in grey in the upper panel for comparison (note the difference in scales). The global meteoric water line (GWML; Craig, 1961) and the linear fit to the precipitation data are shown in blue and in grey, respectively.

CWS regulates inlet air and water temperatures using Peltier thermoelectric controllers.

Figure 6a illustrates that the isotopic composition of precipitation varied over a range of $15.72 \%$ in $\delta^{18} \mathrm{O}$ and $115.63 \%$ in $\delta^{2} \mathrm{H}$. By capturing many precipitation events over weeks to months, our isotope analysis system provides a more detailed insight into the variability of precipitation isotopes compared to previous studies that only monitored individual storms at high frequency (e.g., Moerman et al., 2013; Pangle et al., 2013; Tweed et al., 2016). At our site, a correlation between air temperature and the isotopic composition of precipitation is evident for most storm events. Figure 5 shows that, for instance, precipitation samples became isotopically heavier during Events 2 and 8 when air temperature increased, while the precipitation samples became isotopically lighter during Events 1, 3, and 5, when air temperature decreased. During Events 4, 6, and 7, however, the correlation with temperature was not as distinct as during the other five events.

The isotopic composition of stream water varied by less than half as much as that of precipitation, i.e., by $6.24 \%$ o for $\delta^{18} \mathrm{O}$ and by $45.11 \%$ for $\delta^{2} \mathrm{H}$ (Fig. 6b). For all eight events, the isotopic signature of pre-event stream water was relatively constant, averaging $-11.04 \pm 0.21 \%$ for $\delta^{18} \mathrm{O}$ and $-76.97 \pm 1.46 \%$ ofor $\delta^{2} \mathrm{H}$ ( \pm standard deviation; $\left.n=8\right)$. During the events, $\delta^{18} \mathrm{O}$ and $\delta^{2} \mathrm{H}$ in stream water changed by up to 4.80 and $36.38 \%$, respectively (Event 7 ).

For the IC, memory effects were negligible during the field experiment (because the sample did not make contact with the copper wool), so the measurements were corrected only for drift effects. The solute concentrations in precipitation and stream water varied widely, as shown in Fig. 5. For $\mathrm{Li}^{+}, \mathrm{NH}_{4}^{+}, \mathrm{K}^{+}, \mathrm{F}^{-}$, and $\mathrm{PO}_{4}^{3-}$ in stream water as well as $\mathrm{Mg}^{2+}$ in precipitation, measured concentrations were generally below the LOQ. $\mathrm{Ca}^{2+}, \mathrm{NO}_{3}^{-}$, and $\mathrm{SO}_{4}^{2-}$ in stream water exhibited clear dilution patterns during all precipitation events (Fig. 5e-g). The concentrations of $\mathrm{Ca}^{2+}$, $\mathrm{NO}_{3}^{-}$, and $\mathrm{SO}_{4}^{2-}$ in precipitation during the eight events were on average ( \pm standard deviation) $12.1 \pm 2.9,1.5 \pm 1.1$, and $0.5 \pm 0.8 \mathrm{mg} \mathrm{L}^{-1}$, respectively. The solute concentrations in pre-event stream water were on the order of $( \pm$ standard deviation) $160.8 \pm 9.7 \mathrm{mg} \mathrm{L}^{-1}$ for $\mathrm{Ca}^{2+}, 11.7 \pm 1.8 \mathrm{mg} \mathrm{L}^{-1}$ for $\mathrm{NO}_{3}^{-}$, and $21.5 \pm 3.3 \mathrm{mg} \mathrm{L}^{-1}$ for $\mathrm{SO}_{4}^{2-}$, whereas the concentrations during storm events dropped to values as low as $64.6 \mathrm{mg} \mathrm{L}^{-1}\left(\mathrm{Ca}^{2+}\right), 3.73 \mathrm{mg} \mathrm{L}^{-1}\left(\mathrm{NO}_{3}^{-}\right)$, and $5.12 \mathrm{mg} \mathrm{L}^{-1}$ $\left(\mathrm{SO}_{4}^{2-}\right)$. In contrast, $\mathrm{EC}$ and the concentrations of $\mathrm{Cl}^{-}$(and $\mathrm{Na}^{+}$, not shown) in stream water showed dilution patterns until Event 3 and then showed distinct enrichment patterns thereafter (Fig. 5c-d), likely associated with road salt washoff. Due to possible road-salt effects on $\mathrm{Na}^{+}$and $\mathrm{Cl}^{-}$, we will focus on $\mathrm{Ca}^{2+}, \mathrm{NO}_{3}^{-}$, and $\mathrm{SO}_{4}^{2-}$ in the analysis below.

\section{Comparison of event-water fractions estimated from isotopic and chemical tracers}

\subsection{Hydrograph separation methodology and uncertainty analysis}

To illustrate a potential application of high-frequency isotope and chemical measurements, here we quantify the eventwater fractions of the major events captured during the 1month observation period. We used a two-component endmember mixing analysis by applying the conventional mass balance equation (Pinder and Jones, 1969):

$F_{\mathrm{E}}=\frac{Q_{\mathrm{E}}}{Q_{\mathrm{S}}}=\frac{C_{\mathrm{S}}-C_{\mathrm{P}}}{C_{\mathrm{E}}-C_{\mathrm{P}}}$.

The fraction of event water relative to total streamflow $\left(F_{\mathrm{E}}=Q_{\mathrm{E}} / Q_{\mathrm{S}}\right)$ was calculated from the isotope values or solute concentrations in total streamflow $\left(C_{\mathrm{S}}\right)$, event precipitation $\left(C_{\mathrm{E}}\right)$, and pre-event streamflow $\left(C_{\mathrm{P}}\right)$. Here, $C_{\mathrm{P}}$ was obtained for each event from the average of the five stream water samples immediately before the onset of precipitation. The value of $C_{\mathrm{E}}$ was the incremental, volume-weighted mean (McDonnell et al., 1990) of all precipitation samples that 
were collected before the respective streamflow sample:

$$
C_{\mathrm{E}, j}=\frac{\sum_{i=k}^{j} P_{i} C_{i}}{\sum_{i=k}^{j} P_{i}},
$$

with $P_{i}$ being the precipitation depth associated with the isotope value (or solute concentration) $C_{i}$ collected at time $i$ since the start time $k$ of the precipitation event.

Uncertainty in the hydrograph separation was quantified with Gaussian error propagation (Genereux, 1998), using calculated standard errors (SEs) arising from the analytical uncertainties and the temporal variability of the isotope values (or solute concentrations). Because $C_{\mathrm{E}}$ is a volumeweighted mean, the standard error $\mathrm{SE}_{C_{\mathrm{E}}}$ is calculated with

$\mathrm{SE}_{C_{\mathrm{E}, j}}=\left[\frac{\sum_{i=k}^{j} P_{i}\left(C_{i}-C_{\mathrm{E}, j}\right)^{2}}{(j-k) \sum_{i=k}^{j} P_{i}}\right]^{\frac{1}{2}}$,

where $C_{\mathrm{E}, j}$ denotes the volume-weighted mean, $C_{i}$ denotes the $i$ th concentration that comprises that mean, and $(j)$ is the number of samples included in the volume-weighted mean. The standard error of $C_{\mathrm{S}}$, which is given here as $\mathrm{SE}_{C_{S}}$, arises from the measurement uncertainties given in Table 1. For $\mathrm{SE}_{C_{\mathrm{P}}}$, the same measurement uncertainties are applied, as well as the temporal variability of the five measurements comprising $C_{\mathrm{P}}$. The standard error of the event-water fraction $\left(\mathrm{SE}_{F_{\mathrm{E}}}\right)$ can then be obtained by Gaussian error propagation:

$$
\begin{aligned}
\mathrm{SE}_{F_{\mathrm{E}}} & =\left\{\left[\frac{-1}{C_{\mathrm{P}}-C_{\mathrm{E}}} \mathrm{SE}_{C_{\mathrm{S}}}\right]^{2}+\left[\frac{C_{\mathrm{S}}-C_{\mathrm{E}}}{\left(C_{\mathrm{P}}-C_{\mathrm{E}}\right)^{2}} \mathrm{SE}_{C_{\mathrm{P}}}\right]^{2}\right. \\
& \left.+\left[\frac{C_{\mathrm{P}}-C_{\mathrm{S}}}{\left(C_{\mathrm{P}}-C_{\mathrm{E}}\right)^{2}} \mathrm{SE}_{C_{\mathrm{E}}}\right]^{2}\right\}^{1 / 2} .
\end{aligned}
$$

Isotope hydrograph separation (IHS) was performed using both $\delta^{18} \mathrm{O}$ and $\delta^{2} \mathrm{H}$, whereas chemical hydrograph separation (CHS) was carried out with the three constituents $\mathrm{Ca}^{2+}$, $\mathrm{NO}_{3}^{-}$, and $\mathrm{SO}_{4}^{2-}\left(\mathrm{Cl}^{-}\right.$and $\mathrm{Na}^{+}$were not used for CHS due to the influence of road salt at the site) as well as stream water EC. EC was used here since several studies have applied EC in lieu of chemical concentrations for hydrograph separation, owing to the ease of obtaining continuous EC measurements (e.g., Dzikowski and Jobard, 2012; Matsubayashi et al., 1993; Muñoz-Villers and McDonnell, 2012; Pellerin et al., 2008). As we did not measure EC in precipitation directly, we had to estimate it empirically. For this, we used a standard conversion equation, i.e., the pseudo-linear approach following Sposito (2008), to calculate EC in precipitation from the ionic strength of the major cations and anions in the precipitation samples. We assume that the ion concentrations measured by the IC account for the great majority of the ionic strength. In order to estimate the uncertainty of this method, we also calculated the EC values in stream water and compared them with the actual measurements of the EC probe in the stream. The (absolute value) difference between the calculated and measured stream water EC values averaged $20 \mu \mathrm{S} \mathrm{cm}^{-1}$.

For the uncertainty analysis of the calculated event-water fractions, the analytical uncertainties in the isotope measurements were assumed to be 0.03 and $0.17 \%$ for $\delta^{18} \mathrm{O}$ and $\delta^{2} \mathrm{H}$, respectively (Sect. 3.2; Table 1). The relative uncertainties in the IC measurements were $0.006 \cdot C+0.087 \mathrm{mg} \mathrm{L}^{-1}$ for $\mathrm{Ca}^{2+}, \quad 0.028 \cdot C+0.002 \mathrm{mg} \mathrm{L}^{-1}$ for $\mathrm{NO}_{3}^{-}$, and $0.037 \cdot C+0.006 \mathrm{mg} \mathrm{L}^{-1}$ for $\mathrm{SO}_{4}^{2-}$ (where $C$ is the concentration in $\mathrm{mgL}^{-1}$; Table 1). For the EC values, a measurement uncertainty of $2 \%$ was assumed for the EC probe based on the specifications given by the EC probe's manufacturer. The assumed uncertainty in the EC values in precipitation was $20 \mu \mathrm{S} \mathrm{cm}^{-1}$, as calculated above.

\subsection{Event-water fractions for eight storm events}

A mixing analysis for two endmembers, event water and pre-event water, was carried out for eight storm events between 20 February and 8 March 2016 based on isotopic and chemical tracers. Event 8, where precipitation fell partly as snow, was included in the analysis because river discharge and stream water EC responded within $4 \mathrm{~h}$ after the onset of precipitation (Table 2). Hence, the temporal change in the snowmelt isotopic signal due to fractionation was assumed to be negligible. Two storm events are analyzed in more detail, followed by a general discussion of the hydrograph separation results based on all eight events.

\subsubsection{Two storm events}

Figures 7 and 8 show the hydrologic, isotopic, and chemical responses in stream water and precipitation during Events 1 and 2. During Event 1, total rainfall was $6.8 \mathrm{~mm}$ within $6 \mathrm{~h}$, while $11.5 \mathrm{~mm}$ of rain fell within $13 \mathrm{~h}$ during Event 2 . Antecedent moisture conditions, as inferred from the total rainfall within 48 and $24 \mathrm{~h}$ before the event as well as the initial stream water level, were relatively wet for Event 1 and relatively dry for Event 2 (Table 2).

For Event $1, \delta^{18} \mathrm{O}$ and $\delta^{2} \mathrm{H}$ in stream water followed the observed patterns in precipitation; i.e., stream water became isotopically lighter over time. Isotope hydrograph separation (IHS) for this event yielded maximum event-water fractions $\left(F_{\mathrm{E}, \max }\right)$ of $80 \pm 11$ and $59 \pm 14 \%$ for $\delta^{18} \mathrm{O}$ and $\delta^{2} \mathrm{H}$, respectively. This is similar to the results obtained from the chemical tracers $\mathrm{Ca}^{2+}, \mathrm{NO}_{3}^{-}$, and $\mathrm{SO}_{4}^{2-}(57 \pm 1,65 \pm 2$, and $65 \pm 3 \%)$ and $\mathrm{EC}(56 \pm 3 \%$; Fig. $7 \mathrm{~d}$ and e). The larger uncertainties in the IHS compared to CHS can be explained by the large temporal variability of the isotope values in precipitation, which substantially exceeds the analytical uncertainty. During Event 1, the fraction of event water increased 


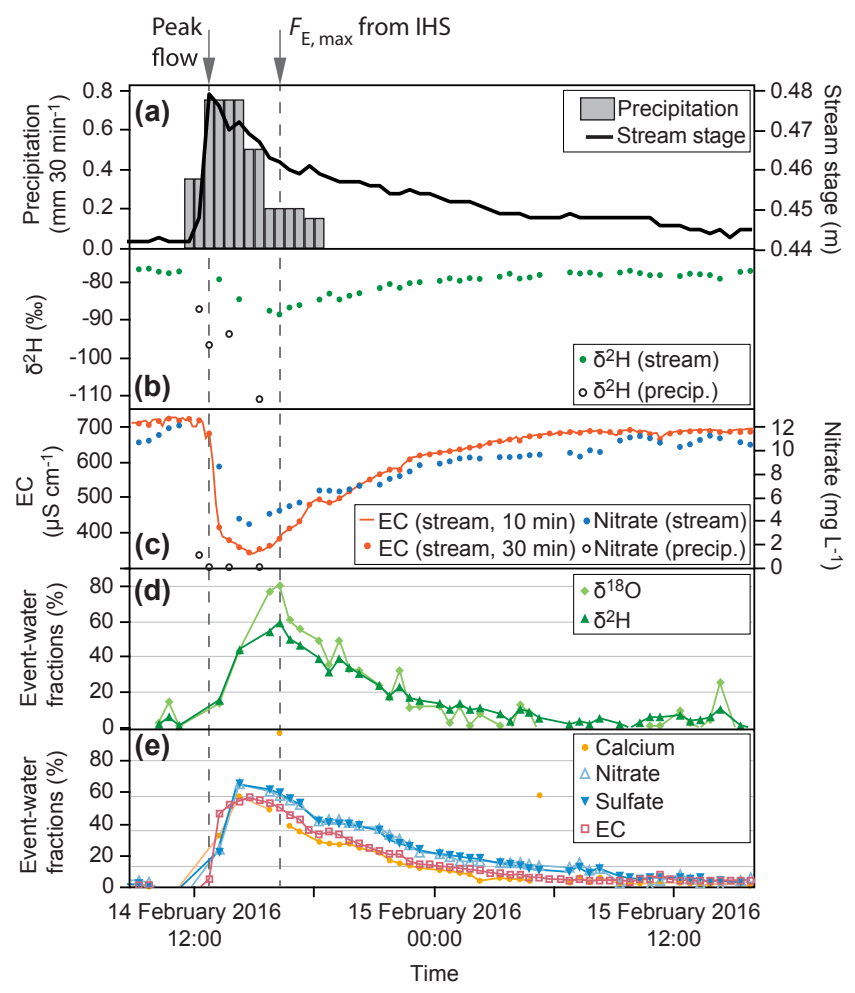

Figure 7. Precipitation Event 1 together with the (a) hydrologic, (b) isotopic, and (c) chemical responses in stream water. Panels (d) and (e) show the fractions of event water based on isotopic and chemical hydrograph separation, respectively, which are similar for both types of tracers. However, the timing of the maximum event-water fraction $\left(F_{\mathrm{E}, \max }\right)$ differs, with the isotopes indicating the largest contribution of event water around $3 \mathrm{~h}$ after the peak flow was reached. In panel (e), the gaps in the $F_{\mathrm{E}}$ time series based on calcium concentrations are due to measurement outliers.

rapidly after the start of rainfall and declined continuously as the stream stage receded. A difference in timing of $F_{\mathrm{E}, \max }$ was evident for both tracer types (Fig. 7d-e): $F_{\mathrm{E} \text {,max }}$ based on the chemical tracers occurred $1 \mathrm{~h}$ after the peak flow, whereas $F_{\mathrm{E} \text {,max }}$ based on the isotope tracers was delayed by roughly $3 \mathrm{~h}$, possibly because the isotopic signature in precipitation became lighter as the event progressed. Consequently, if $C_{\mathrm{S}}$ values at the time of peak flow were used to perform hydrograph separation (Eq. 3), the isotope-based $F_{\mathrm{E}}$ values would be substantially smaller (i.e., $13 \pm 4$ and $15 \pm 3 \%$ for $\delta^{18} \mathrm{O}$ and $\delta^{2} \mathrm{H}$, respectively) than the $F_{\mathrm{E}, \max }$ values reported above.

During Event 2, the solutes in stream water showed a clear dilution signal (Fig. 8c) similar to Event 1. The isotopic composition in stream water, by contrast, showed only a very weak and inconsistent response to precipitation. For instance, $\delta^{2} \mathrm{H}$ in precipitation increased continuously through the event, whereas $\delta^{2} \mathrm{H}$ in stream water first decreased and then began to increase again several hours after the onset of precipitation. Consequently, IHS and CHS yielded substantially different interpretations of Event 2 . The maximum

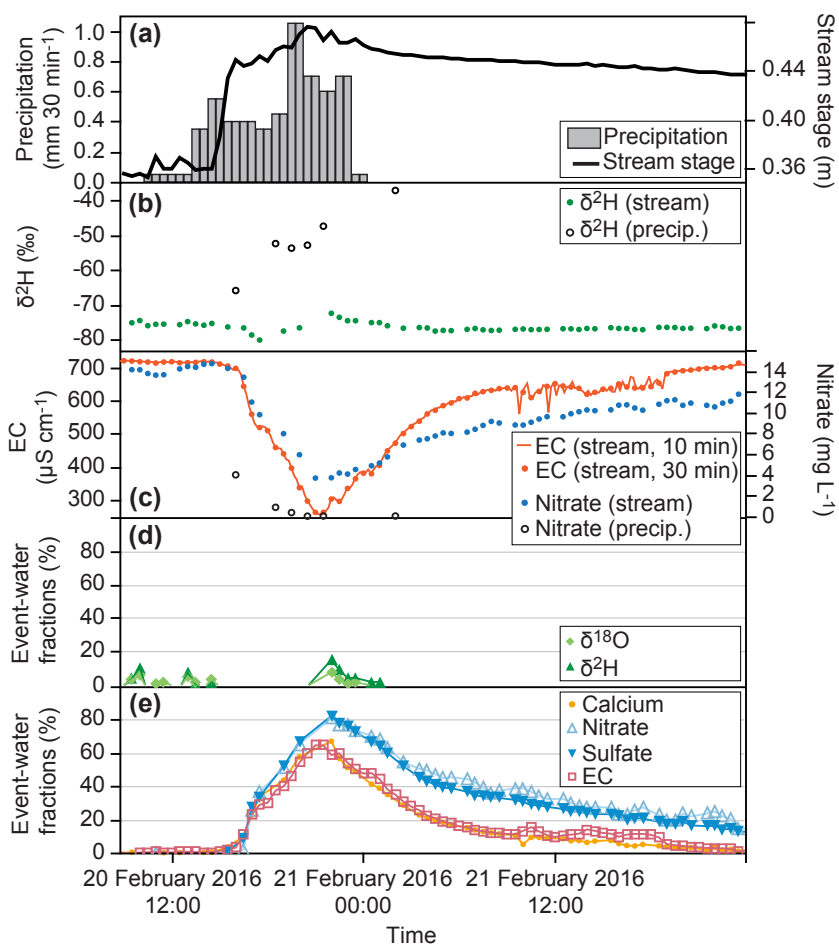

Figure 8. Precipitation Event 2 and the (a) hydrologic, (b) isotopic, and (c) chemical responses in stream water. Panels (d) and (e) show the fractions of event water $\left(F_{\mathrm{E}}\right)$ based on isotopic and chemical hydrograph separation. Chemical tracers greatly exaggerate the eventwater fraction.

event-water fractions based on CHS ranged from $67 \pm 1 \%$ $\left(\mathrm{Ca}^{2+}\right)$ to $82 \pm 3 \%\left(\mathrm{SO}_{4}^{2-}\right)$, similar to Event 1 . In contrast, $F_{\mathrm{E} \text {,max }}$ values based on IHS ranged from $8 \pm 1$ to $15 \pm 3 \%$, indicating that pre-event water was the dominant source of stream water during peak flow.

How can such a large discrepancy between the event-water fractions calculated from different environmental tracers be explained? From Fig. 5 it can be seen that precipitation was isotopically lighter than stream water in the 6 days leading up to Event 2. Thus, the initial decrease in the $\delta^{18} \mathrm{O}$ and $\delta^{2} \mathrm{H}$ values in stream water during Event 2 suggests the release of isotopically lighter soil water and groundwater that were recharged during previous events. An activation of this preevent water storage might have been triggered by enhanced infiltration after relatively dry antecedent moisture conditions (AMC) compared to the previous event, whereas wet AMC would be more consistent with surface runoff generation. This hypothesis is further supported by the isotopic responses in stream water during Event 5, another isotopically heavy event with dry AMC, following earlier inputs of isotopically lighter precipitation. In Event 5, small event-water fractions $\left(12 \pm 1\right.$ and $21 \pm 1 \%$ for $\delta^{18} \mathrm{O}$ and $\delta^{2} \mathrm{H}$, respectively; Fig. S1 in the Supplement) were again obtained, indicating that pre-event water dominated streamflow, similar to Event 2. In Event 5, just as in Event 2, the chemical trac- 

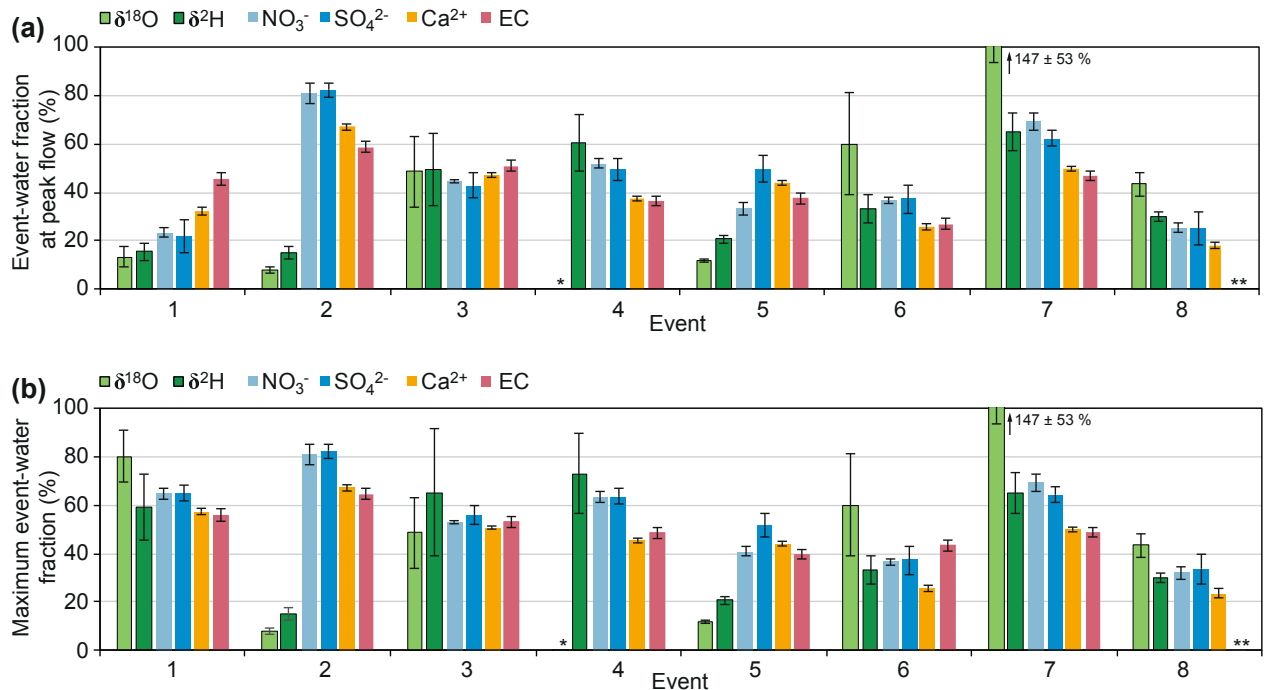

Figure 9. Event-water fractions $\left(F_{\mathrm{E}}\right)$ based on isotopic and chemical hydrograph separation for eight storm events. Panel (a) shows $F_{\mathrm{E}}$ during peak flow, and panel (b) shows the maximum event-water fractions $\left(F_{\mathrm{E}, \text { max }}\right)$ of each event. Unrealistic $F_{\mathrm{E}}$ and $F_{\mathrm{E} \text {, max }}$ values based on $\delta{ }^{18} \mathrm{O}$ were obtained for Event 4 because the isotopic signatures in precipitation and pre-event stream water were too similar $(*)$. For Event 8 , the wash-off of road salt resulted in unrealistic $F_{\mathrm{E}}$ and $F_{\mathrm{E} \text {, max }}$ values based on EC: $-96 \pm 6$ and $-95 \pm 6 \%$ (**), respectively. The larger uncertainties in the IHS results compared to CHS can be explained by the large temporal variability of the isotope values in precipitation, which substantially exceeds the analytical uncertainty during most events.

ers showed strong dilution, leading to an overestimate of the maximum event-water fraction ( $>40 \pm 2 \%$ ). In both Event 2 and Event 5, the chemical and isotopic data indicate a large contribution from recent soil water or groundwater that had not yet become highly mineralized, rather than from either event precipitation or from older groundwater that presumably accounted for most of the pre-event baseflow.

\subsubsection{General discussion of hydrograph separation results}

Figure 9 summarizes the estimated event-water fractions for all eight events, based on IHS and CHS, for two points in time during each event: the time with the largest isotopic or chemical response (i.e., $F_{\mathrm{E} \text {,max }}$ ) and the time of peak flow. Maximum event-water fractions varied greatly across the eight events (for example, from $15 \pm 3$ to $73 \pm 17 \%$ based on $\delta^{2} \mathrm{H}$; Fig. 9; Tables S1 and S2 in the Supplement). Also, within individual events, hydrograph separations based on different isotopic and chemical tracers differed, often by much more than their uncertainties. The inconsistencies between the estimated event-water fractions can be explained by the fact that different tracers are shaped by different hydrochemical processes and flow pathways and thus may describe different endmembers (Richey et al., 1998; Wels et al., 1991). While stable water isotopes are considered to be ideal conservative tracers, chemical tracers are altered by biogeochemical processes on their way through hydrological systems. These biogeochemical processes also vary over time, as they depend on antecedent conditions and precipitation characteristics. The high-frequency analysis of environmental tracers can document this temporal variability, which, in turn, helps to constrain conceptual catchment models. As illustrated by Events 2 and 5, comparing chemical and isotopic tracers can be useful in identifying the temporally variable contributions of different water storages in the subsurface.

For Event 7, IHS based on $\delta^{18} \mathrm{O}$ resulted in eventwater fractions of $>100 \%$, which can be explained by the fact that the first precipitation sample from this event was isotopically very similar to the pre-event water signature $\left(C_{\mathrm{E}}=-11.69 \%\right.$ o, $C_{\mathrm{P}}=-11.09 \%$ o $)$. The incremental, volume-weighted mean of the event-water endmember was thus isotopically heavier than the stream water endmember, resulting in a smaller difference from the pre-event water endmember signature (Eq. 3). The precipitation samples after this first, less $\delta^{18} \mathrm{O}$-depleted sample had an average $\delta^{18} \mathrm{O}$ value of $-16.86 \pm 0.73 \%$ ( \pm standard deviation; $n=6$ ). For $\delta^{2} \mathrm{H}$, such a strong effect did not occur, and we could obtain reasonable isotope-based hydrograph separation results similar to the chemical hydrograph separation.

Figure 9 illustrates further that for three events $(2,5$, and $8)$, the estimated event-water fractions for the two isotopes $\delta^{18} \mathrm{O}$ and $\delta^{2} \mathrm{H}$ differed significantly (i.e., by more than twice their pooled uncertainties). These differences did not follow any particular pattern; for instance, $F_{\mathrm{E}}\left(\delta^{18} \mathrm{O}\right)>F_{\mathrm{E}}\left(\delta^{2} \mathrm{H}\right)$ for Event 8 , while $F_{\mathrm{E}}\left(\delta^{18} \mathrm{O}\right)<F_{\mathrm{E}}\left(\delta^{2} \mathrm{H}\right)$ for Events 2 and 5 . Such discrepancies might be caused by temporally variable $\delta^{18} \mathrm{O}-\delta^{2} \mathrm{H}$ relations ( $d$ excess) of contributing water sources (groundwater, soil water, and overland flow), resulting in different event-water fractions based on both isotopes. An al- 


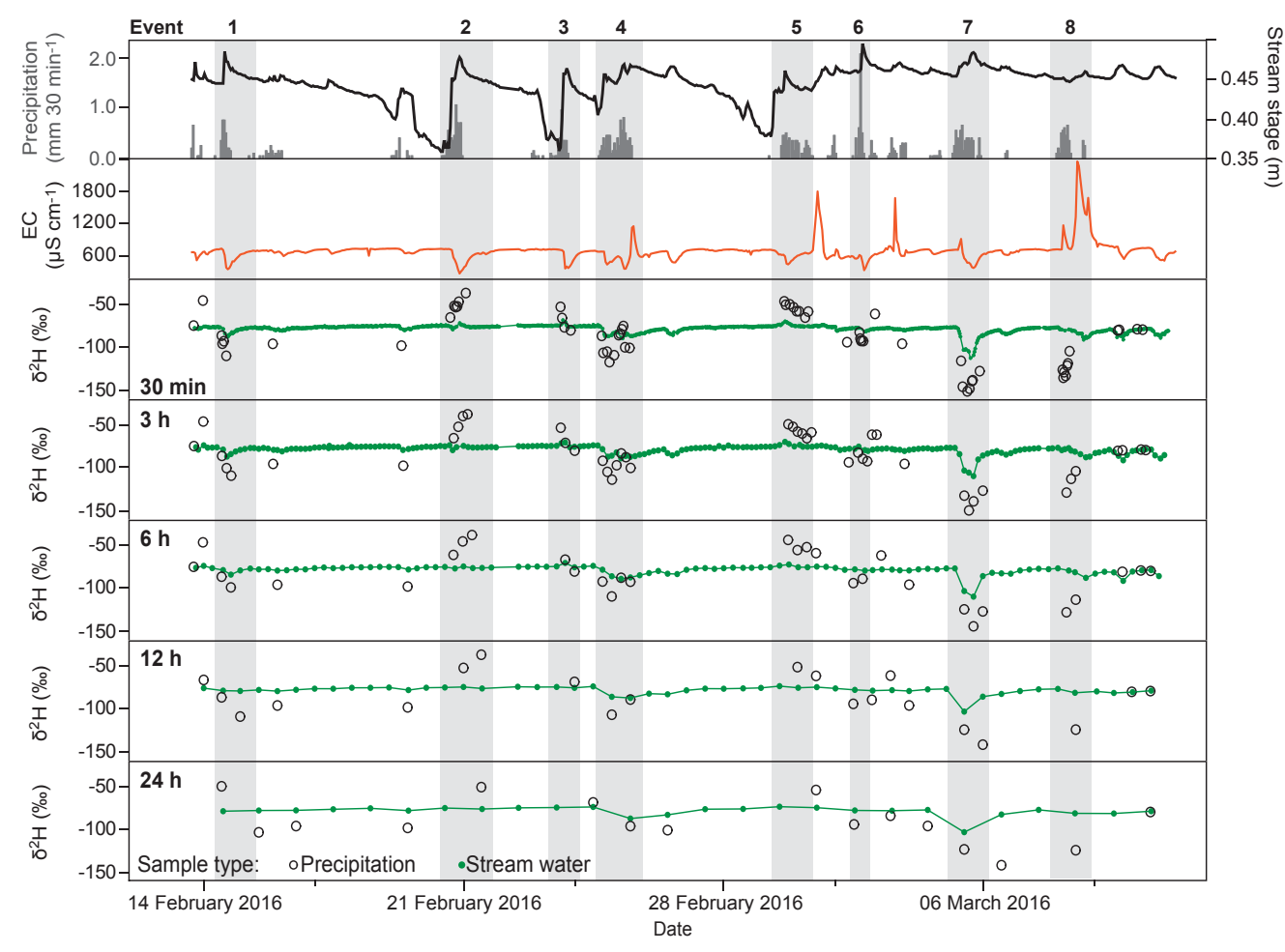

Figure 10. Time series of precipitation, stream stage, and stream water EC, as well as $\delta^{2} \mathrm{H}$ values in stream water and precipitation at sampling intervals of $30 \mathrm{~min}$ and $3,6,12$, and $24 \mathrm{~h}$. The stream water isotope values at $3-24 \mathrm{~h}$ temporal resolution were obtained by subsampling from the $30 \mathrm{~min}$ time series. To mimic the effects of integrated bulk precipitation samples, the isotope values in precipitation were calculated by volume-weighted averaging the $30 \mathrm{~min}$ data over the corresponding time intervals. The vertical grey bars indicate the periods of the eight precipitation events used for hydrograph separation.

ternative explanation is that the pre-event streamflow signature $\left(C_{\mathrm{P}}\right)$ may not reflect the isotopic signature of the entire pre-event water storage, but only of the components that feed baseflow (Klaus and McDonnell, 2013). Another way of viewing this problem is that the precipitation event may have mobilized a third pre-event water storage with unknown isotopic composition (Tetzlaff et al., 2014). This conjecture is strongly supported by the initial shift toward isotopically lighter streamflow early in Event 2, even though the event precipitation was isotopically heavier than the preevent baseflow. Event 5 also showed divergent event-water fractions between the two isotopes, and like Event 2, it also had strongly contrasting pre-event precipitation inputs. Thus, the history of both events suggests that pre-event storage in this catchment was isotopically heterogeneous. This observation is unsurprising given the pervasive heterogeneity of typical catchments, but a more detailed explanation is not possible with our spatially limited data set. Spatially distributed measurements, such as from groundwater and soil water storages, would help to constrain the individual endmembers that contribute to streamflow (e.g., Hangen et al., 2001). Additional high-frequency time series of the groundwater table and soil moisture profiles would allow for documenting of the effects of antecedent moisture conditions on the response times and on the activation of different storages at the site. Finally, a spatially distributed precipitation sampling network might help to fully quantify the uncertainty inherent in the event-water signature (Fischer et al., 2017; Lyon et al., 2009).

\subsection{The role of the sampling frequency in capturing hydrological and hydrochemical catchment processes}

A sampling frequency can be considered optimal when the gain of information from additional measurements is marginal (Kirchner et al., 2004; Neal et al., 2012). With our high-resolution data set, we can thus investigate the potential of different sampling frequencies for capturing hydrological and hydrochemical catchment processes by subsampling the 30 min time series at smaller sampling frequencies, i.e., at 3 , 6 , and $12 \mathrm{~h}$ and daily intervals. To mimic the effects of integrated bulk precipitation samples, we calculated the volumeweighted averages of concentrations and isotope values in precipitation over the corresponding time intervals.

Figure 10 shows that $3 \mathrm{~h}$ sampling frequencies would still be sufficient to capture the isotopic variations in stream water, including during low-intensity precipitation events. However, the short-term variability within single storm periods, 

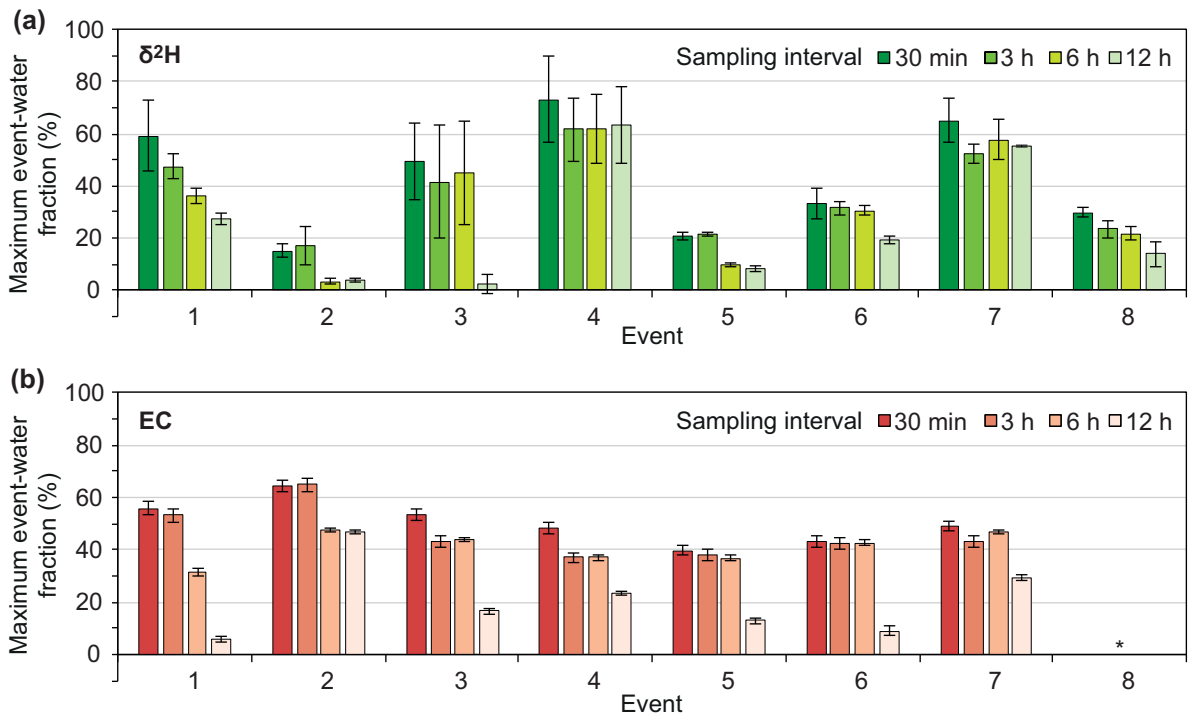

Figure 11. Maximum event-water fractions at sampling intervals of $30 \mathrm{~min}$ and $3 \mathrm{~h}, 6 \mathrm{~h}$, and $12 \mathrm{~h}$ based on (a) $\delta^{2} \mathrm{H}$ and (b) EC. With lower sampling frequencies, the event-water fractions are often underestimated or become unrealistic, as the likelihood increases that the point of the largest $\delta^{2} \mathrm{H}$ or EC variations in streamflow will be missed (stream water $\delta^{2} \mathrm{H}$ and EC time series were subsampled at $3 \mathrm{~h}, 6 \mathrm{~h}$, and $12 \mathrm{~h}$ and daily intervals; concentrations of integrated bulk precipitation samples were calculated from the volume-weighted averages over the respective time interval). For Event 8 , the wash-off of road salt resulted in unrealistic $F_{\mathrm{E} \text {, max }}$ values based on EC $(*)$.

as well as the rapid changes in precipitation isotope values, cannot be resolved at this lower sampling frequency. Thus, even sampling intervals of $3 \mathrm{~h}$ can result in a significant loss of information relative to $30 \mathrm{~min}$ sampling, and at sampling intervals of $12 \mathrm{~h}$ or longer, diurnal fluctuations and some isotopic and chemical responses to low-intensity precipitation events would also be lost. Likewise, the $6 \mathrm{~h}$ or $12 \mathrm{~h}$ bulk precipitation samples shown in Fig. 10 fail to reflect the large isotopic variability revealed by the $30 \mathrm{~min}$ samples.

To further illustrate the effect of lower sampling frequencies, we performed hydrograph separation with the subsampled data sets, for which illustrative results of the maximum event-water fractions are shown for $\delta^{2} \mathrm{H}$ and EC in Fig. 11. With a sampling frequency of $3 \mathrm{~h}$, maximum event-water fractions similar to those for the $30 \mathrm{~min}$ sampling can still be obtained, except for Events 3 (EC) and 4 (EC), where $F_{\mathrm{E} \text {,max }}$ is underestimated. Longer sampling intervals $(6 \mathrm{~h}, 12 \mathrm{~h}) \mathrm{re}-$ sult in much smaller event-water fractions for most events. Because the hydrologic response times in this catchment were only between $0 \mathrm{~h}$ and $2.5 \mathrm{~h}$, the durations of the maximum hydrochemical variations were similarly short. Consequently, sampling at longer time intervals increases the risk of missing this critical peak response; if the sample is taken before or after the maximum hydrochemical response, the event-water signal in stream water $\left(C_{\mathrm{S}}\right)$ may be too weak, which will inevitably underestimate the event-water fractions or even lead to unrealistic negative values. Furthermore, the rapid changes observed in precipitation isotopic composition (Fig. 6) suggest that high-frequency measurements are crucial to adequately represent the signature of the event-water endmember. Capturing the short-term responses of environmental tracers also helps to better quantify transit time distributions (Birkel et al., 2012; Stockinger et al., 2016; Timbe et al., 2015) and to constrain concentration-discharge models (Stelzer and Likens, 2006; Jones et al., 2012).

Our data also show that peak flow is not always a reliable predictor of the time at which $F_{\mathrm{E}}$ becomes largest. As can be seen, for example, during Event 1 (Fig. 7), $F_{\mathrm{E} \text {,max }}$ based on IHS occurred up to $3.0 \pm 1.0 \mathrm{~h}$ after the peak flow. The timing of the peak flow and the $F_{\mathrm{E} \text {,max }}$ values for chemical and isotope tracers coincided for only four events (Events 2, 6, 7, and 8). During the remaining events, the tracer signal showed the strongest responses up to $2.5 \pm 1.0 \mathrm{~h}$ after the peak flow, indicating that the time window for sample collection at our site must extend more than $3 \mathrm{~h}$ before and after the peak flow in order to capture the whole range of event-water dynamics. In the case of snowmelt Event 8, when the maximum EC response occurred $5 \mathrm{~h}$ before the peak flow, an even longer sampling period would be required in order to capture unusual events, such as the inflow of water contaminated by road salt.

\section{Concluding remarks}

This paper presents the first field hydrology application of Picarro's Continuous Water Sampler (CWS), which was coupled to a L2130-i wavelength-scanned cavity ring-down spectrometer to measure $\delta^{18} \mathrm{O}$ and $\delta^{2} \mathrm{H}$ in stream water and precipitation at a temporal resolution of $30 \mathrm{~min}$. We com- 
bined this real-time isotope analysis system with a dualchannel ion chromatograph for the synchronous analysis of major cations and anions. Good instrument performance and high measurement precision could be achieved during continuous $48 \mathrm{~h}$ laboratory experiments and a 28-day deployment in the field at a small, partly urbanized catchment in central Switzerland.

Problematic issues, such as sample degradation during storage and transportation that arise in conventional sampling for catchment tracer studies, become irrelevant with the system presented here. At the same time, potential registration errors arising during the collection and handling of a large number of water samples are avoided. Conversely, two major limitations of the coupled isotope analyzer/IC system are its high cost and the need for line power, which constrains its use in remote locations. However, the laboratory analysis of conventionally collected grab samples is also cost-intensive, and the autosamplers used in conventional sampling schemes also require a reliable energy supply (though at much lower power levels).

The results of the high-frequency analysis system are presented here to provide a proof-of-concept and an illustration of its functionality in the field, rather than to fully document the hydrological and biogeochemical processes at this field site. A more detailed interpretation would require additional measurements of soil water and groundwater isotopes and chemistry in order to better constrain the endmembers in the mixing analysis. Nevertheless, our 1-month field experiment demonstrates the marked short-term variability of several natural tracers in a small, highly dynamic watershed. The hydrograph separation exercise clearly showed that long-term, high-frequency isotopic and chemical analyses are essential for capturing the "unusual but informative" events that shed light on catchment storage and flow processes. We further showed that the right timing for capturing peak event-water contributions can easily be missed with conventional grab sampling strategies at time intervals longer than $3 \mathrm{~h}$, resulting in an underestimation of the event-water fraction. In addition, the relative timing of the isotopic and chemical responses was highly variable, demonstrating the challenge of capturing the right moments with episodic snapshot campaigns or long-term monitoring with daily, weekly, or even monthly sampling intervals.

As was shown here and elsewhere (e.g., Kirchner, 2003), the short-term responses of streamflow and environmental tracers may follow distinctly different patterns, which helps to constrain streamflow generation mechanisms and quantifying short transit times. Thus, high-frequency isotopic and chemical measurements also have great potential for catchment model validation. Potential future applications of the system could include sites with rapid hydrologic responses, such as urban streams (e.g., Jarden et al., 2016; Jefferson et al., 2015; Soulsby et al., 2014), wastewater and drinking water systems (e.g., Houhou et al., 2010; Kracht et al., 2007), or agricultural catchments with artificial drainage networks (e.g., Doppler et al., 2012; Heinz et al., 2014). By eliminating the errors associated with the handling, transportation, and storage of individual bottles, our analysis system may also achieve better precision than conventional field sampling followed by laboratory analyses. As a result, our system may be able to detect subtle isotopic and biogeochemical signals (associated with, e.g., evaporation effects or in-stream biological processes) that would be missed by conventional approaches to sampling and analysis. Thus, this system can potentially shed new light on the linkages between hydrological, biological, and geochemical processes.

\section{Data availability}

The data sets can be found in the Supplement to this article.

\section{The Supplement related to this article is available online at doi:10.5194/hess-21-1721-2017-supplement.}

Competing interests. The authors declare that they have no conflict of interest.

Acknowledgements. We thank Anton Burkhardt and the facility staff of the Swiss Federal Institute for Forest, Snow and Landscape Research (WSL) for logistical support, and Matthias Haeni from the Long-term Forest Ecosystem Research Programme (LWF) at WSL for providing air temperature data. We also thank Barbara Herbstritt of the isotope laboratory at the University Freiburg (Germany) for the analysis of the isotope reference standards, as well as Kate Dennis and David Kim-Hak of Picarro Inc. (Santa Clara, CA, USA) for technical advice.

Edited by: M. Weiler

Reviewed by: N. Munksgaard and one anonymous referee

\section{References}

Aubert, A. H., Gascuel-Odoux, C., Gruau, G., Akkal, N., Faucheux, M., Fauvel, Y., Grimaldi, C., Hamon, Y., Jaffrézic, A., Lecoz-Boutnik, M., Molénat, J., Petitjean, P., Ruiz, L., and Merot, P.: Solute transport dynamics in small, shallow groundwater-dominated agricultural catchments: insights from a high-frequency, multisolute $10 \mathrm{yr}$-long monitoring study, Hydrol. Earth Syst. Sci., 17, 1379-1391, doi:10.5194/hess-17-13792013, 2013.

Aubert, A. H. and Breuer, L.: New seasonal shift in in-stream diurnal nitrate cycles identified by mining high-frequency data, PLoS ONE, 11, e0153138, doi:10.1371/journal.pone.0153138, 2016.

Bende-Michl, U. and Hairsine, P. B.: A systematic approach to choosing an automated nutrient analyser for river monitoring, J. Environ. Monitor., 12, 127-134, 2010. 
Benettin, P., Kirchner, J. W., Rinaldo, A., and Botter, G.: Modeling chloride transport using travel time distributions at Plynlimon, Wales, Water Resour. Res., 51, 3259-3276, doi:10.1002/2014WR016600, 2015.

Berman, E. S. F., Gupta, M., Gabrielli, C., Garland, T., and McDonnell, J. J.: High-frequency field-deployable isotope analyzer for hydrological applications, Water Resour. Res., 45, W10201, doi:10.1029/2009wr008265, 2009.

Birkel, C., Soulsby, C., Tetzlaff, D., Dunn, S., and Spezia, L.: Highfrequency storm event isotope sampling reveals time-variant transit time distributions and influence of diurnal cycles, Hydrol. Process., 26, 308-316, doi:10.1002/hyp.8210, 2012.

Buso, D. C., Likens, G. E., and Eaton, J. S.: Chemistry of precipitation, streamwater, and lakewater from the Hubbard Brook Ecosystem Study: a record of sampling protocols and analytical procedures, USDA Forest Service, Northeastern Research Station, USDA Forest Service, Newtown Square, PA., Gen. Tech. Rep. NE-275, 52 pp., 2000.

Craig, H.: Isotopic variations in meteoric waters, Science, 133, 1702-1703, 1961.

Darling, W. G. and Bowes, M. J.: A long-term study of stable isotopes as tracers of processes governing water flow and quality in a lowland river basin: the upper Thames, UK, Hydrol. Process., 30, 2178-2195, doi:10.1002/hyp.10779, 2016.

Doppler, T., Camenzuli, L., Hirzel, G., Krauss, M., Lück, A., and Stamm, C.: Spatial variability of herbicide mobilisation and transport at catchment scale: insights from a field experiment, Hydrol. Earth Syst. Sci., 16, 1947-1967, doi:10.5194/hess-161947-2012, 2012.

Dzikowski, M. and Jobard, S.: Mixing law versus discharge and electrical conductivity relationships: application to an alpine proglacial stream, Hydrol. Process., 26, 2724-2732, doi:10.1002/Hyp.8366, 2012.

Fischer, B. M. C., van Meerveld, I., and Seibert, J.: Spatial variability in the isotopic composition of rainfall in a small headwater catchment and its effect on hydrograph separation, J. Hydrol., doi:10.1016/j.jhydrol.2017.01.045, 2017.

Genereux, D.: Quantifying uncertainty in tracer-based hydrograph separations, Water Resour. Res., 34, 915-919, 1998.

GIS-ZH: Geographisches Informationssystem des Kantons Zürich (GIS-ZH), Amt für Raumentwicklung, Abteilung Geoinformation, GIS-Produkte GIS-Browser, Map, available at: http://maps. zh.ch/, last access: 4 October 2016.

Gupta, P., Noone, D., Galewsky, J., Sweeney, C., and Vaughn, B. H.: Demonstration of high-precision continuous measurements of water vapor isotopologues in laboratory and remote field deployments using wavelength-scanned cavity ring-down spectroscopy (WS-CRDS) technology, Rapid Commun. Mass Sp., 23, 25342542, doi:10.1002/rcm.4100, 2009.

Haeni, M.: Air Temperature and Precipitation data (1 February to 14 March 2016) from the WSL Uitikon forest meteorological station, in 10 and 30 minute time resolution, dataset, available at: https://doi.org/10.13140/RG.2.2.11510.60480, 2016.

Halliday, S. J., Skeffington, R. A., Wade, A. J., Neal, C., Reynolds, B., Norris, D., and Kirchner, J. W.: Upland streamwater nitrate dynamics across decadal to sub-daily timescales: a case study of Plynlimon, Wales, Biogeosciences, 10, 8013-8038, doi:10.5194/bg-10-8013-2013, 2013.
Hangen, E., Lindenlaub, M., Leibundgut, C., and von Wilpert, K.: Investigating mechanisms of stormflow generation by natural tracers and hydrometric data: a small catchment study in the Black Forest, Germany, Hydrol. Process., 15, 183-199, 2001.

Harman, C. J.: Time-variable transit time distributions and transport: Theory and application to storage-dependent transport of chloride in a watershed, Water Resour. Res., 51, 1-30, doi:10.1002/2014WR015707, 2015.

Hayashi, M., Vogt, T., Mächler, L., and Schirmer, M.: Diurnal fluctuations of electrical conductivity in a pre-alpine river: Effects of photosynthesis and groundwater exchange, J. Hydrol., 450, 93 104, doi:10.1016/J.Jhydrol.2012.05.020, 2012.

Heinz, E., Kraft, P., Buchen, C., Frede, H. G., Aquino, E., and Breuer, L.: Set Up of an Automatic Water Quality Sampling System in Irrigation Agriculture, Sensors-Basel, 14, 212-228, doi:10.3390/S140100212, 2014.

Herbstritt, B., Gralher, B., and Weiler, M.: Continuous in situ measurements of stable isotopes in liquid water, Water Resour. Res., 48, W03601, doi:10.1029/2011wr011369, 2012.

Houhou, J., Lartiges, B. S., France-Lanord, C., Guilmette, C., Poix, S., and Mustin, C.: Isotopic tracing of clear water sources in an urban sewer: A combined water and dissolved sulfate stable isotope approach, Water Res., 44, 256-266, doi:10.1016/j.watres.2009.09.024, 2010

Jarden, K. M., Jefferson, A. J., and Grieser, J. M.: Assessing the effects of catchment-scale urban green infrastructure retrofits on hydrograph characteristics, Hydrol. Process., 30, 1536-1550, doi:10.1002/hyp.10736, 2016.

Jasechko, S., Kirchner, J. W., Welker, J. M., and McDonnell, J. J.: Substantial proportion of global streamflow less than three months old, Nat. Geosci., 9, 126-129, doi:10.1038/Ngeo2636, 2016.

Jefferson, A. J., Bell, C. D., Clinton, S. M., and McMillan, S. K.: Application of isotope hydrograph separation to understand contributions of stormwater control measures to urban headwater streams, Hydrol. Process., 29, 5290-5306, doi:10.1002/hyp.10680, 2015.

Jones, A. S., Horsburgh, J. S., Mesner, N. O., Ryel, R. J., and Stevens, D. K.: Influence of Sampling Frequency on Estimation of Annual Total Phosphorus and Total Suspended Solids Loads, J. Am. Water Resour. Assoc., 48, 1258-1275, doi:10.1111/j.1752-1688.2012.00684.x, 2012.

Kendall, C. and McDonnell, J. J.: Isotope tracers in catchment hydrology, Elsevier, Amsterdam, New York, xxix, 839 pp., 1998.

Kirchner, J. W.: A double paradox in catchment hydrology and geochemistry, Hydrol. Process., 17, 871-874, doi:10.1002/Hyp.5108, 2003.

Kirchner, J. W., Feng, X. H., Neal, C., and Robson, A. J.: The fine structure of water-quality dynamics: the (highfrequency) wave of the future, Hydrol. Process., 18, 1353-1359, doi:10.1002/Hyp.5537, 2004.

Kirchner, J. W. and Neal, C.: Universal fractal scaling in stream chemistry and its implications for solute transport and water quality trend detection, P. Natl. Acad. Sci. USA, 110, 1221312218, doi:10.1073/Pnas.1304328110, 2013.

Klaus, J. and McDonnell, J. J.: Hydrograph separation using stable isotopes: Review and evaluation, J. Hydrol., 505, 47-64, doi:10.1016/j.jhydrol.2013.09.006, 2013. 
Kracht, O., Gresch, M., and Gujer, W.: A Stable Isotope Approach for the Quantification of Sewer Infiltration, Environ. Sci. Technol., 41, 5839-5845, doi:10.1021/es062960c, 2007.

Leibundgut, C. and Seibert, J.: Tracer Hydrology, in: The Science of Hydrology, edited by: Uhlenbrook, S., Treatise on Water Science, Elsevier, Amsterdam, 215-236, 2011.

Lyon, S. W., Desilets, S. L. E., and Troch, P. A.: Characterizing the response of a catchment to an extreme rainfall event using hydrometric and isotopic data, Water Resour. Res., 44, W06413, doi:10.1029/2007wr006259, 2008.

Lyon, S. W., Desilets, S. L. E., and Troch, P. A.: A tale of two isotopes: differences in hydrograph separation for a runoff event when using delta D versus delta O-18, Hydrol. Process., 23, 2095-2101, doi:10.1002/hyp.7326, 2009.

Matsubayashi, U., Velasquez, G. T., and Takagi, F.: Hydrograph separation and flow analysis by specific electrical conductance of water, J. Hydrol., 152, 179-199, doi:10.1016/00221694(93)90145-Y, 1993.

McDonnell, J. J., Bonell, M., Stewart, M. K., and Pearce, A. J.: Deuterium Variations in Storm Rainfall - Implications for Stream Hydrograph Separation, Water Resour. Res., 26, 455458, doi:10.1029/WR026i003p00455, 1990.

McGlynn, B. L. and McDonnell, J. J.: Quantifying the relative contributions of riparian and hillslope zones to catchment runoff, Water Resour. Res., 39, 1310, doi:10.1029/2003wr002091, 2003.

Moerman, J. W., Cobb, K. M., Adkins, J. F., Sodemann, H., Clark, B., and Tuen, A. A.: Diurnal to interannual rainfall $\delta 18 \mathrm{O}$ variations in northern Borneo driven by regional hydrology, Earth Planet. Sc. Lett., 369-370, 108-119, doi:10.1016/j.epsl.2013.03.014, 2013.

Munksgaard, N. C., Wurster, C. M., and Bird, M. I.: Continuous analysis of delta O-18 and delta D values of water by diffusion sampling cavity ring-down spectrometry: a novel sampling device for unattended field monitoring of precipitation, ground and surface waters, Rapid Commun. Mass Sp., 25, 3706-3712, doi:10.1002/rcm.5282, 2011.

Munksgaard, N. C., Wurster, C. M., Bass, A., and Bird, M. I.: Extreme short-term stable isotope variability revealed by continuous rainwater analysis, Hydrol. Process., 26, 3630-3634, doi:10.1002/hyp.9505, 2012.

Muñoz-Villers, L. E. and McDonnell, J. J.: Runoff generation in a steep, tropical montane cloud forest catchment on permeable volcanic substrate, Water Resour. Res., 48, W09528, doi:10.1029/2011WR011316, 2012.

Neal, C., Reynolds, B., Norris, D., Kirchner, J. W., Neal, M., Rowland, P., Wickham, H., Harman, S., Armstrong, L., Sleep, D., Lawlor, A., Woods, C., Williams, B., Fry, M., Newton, G., and Wright, D.: Three decades of water quality measurements from the Upper Severn experimental catchments at Plynlimon, Wales: an openly accessible data resource for research, modelling, environmental management and education, Hydrol. Process., 25, 3818-3830, doi:10.1002/hyp.8191, 2011.

Neal, C., Reynolds, B., Rowland, P., Norris, D., Kirchner, J. W., Neal, M., Sleep, D., Lawlor, A., Woods, C., Thacker, S., Guyatt, H., Vincent, C., Hockenhull, K., Wickham, H., Harman, S., and Armstrong, L.: High-frequency water quality time series in precipitation and streamflow: From fragmentary signals to scientific challenge, Sci. Total Environ., 434, 3-12, doi:10.1016/j.scitotenv.2011.10.072, 2012.
Pangle, L. A., Klaus, J., Berman, E. S. F., Gupta, M., and McDonnell, J. J.: A new multisource and high-frequency approach to measuring $\delta 2 \mathrm{H}$ and $\delta 18 \mathrm{O}$ in hydrological field studies, Water Resour. Res., 49, 7797-7803, doi:10.1002/2013WR013743, 2013.

Pellerin, B. A., Wollheim, W. M., Feng, X., and Vörörsmarty, C. J.: The application of electrical conductivity as a tracer for hydrograph separation in urban catchments, Hydrol. Process., 22, 1810-1818, doi:10.1002/hyp.6786, 2008.

Pinder, G. F. and Jones, J. F.: Determination of the groundwater component of peak discharge from the chemistry of total runoff, Water Resour. Res., 5, 438-445, doi:10.1029/WR005i002p00438, 1969.

Richey, D. G., McDonnell, J. J., Erbe, M. W., and Hurd, T. M.: Hydrograph separations based on chemical and isotopic concentrations: A critical appraisal of published studies from New Zealand, North America and Europe, J. Hydrol., 37, 95-111, 1998.

Riml, J. and Worman, A.: Spatiotemporal decomposition of solute dispersion in watersheds, Water Resour. Res., 51, 2377-2392, doi:10.1002/2014WR016385, 2015.

Rode, M., Angelstein, S. H. N., Anis, M. R., Borchardt, D., and Weitere, M.: Continuous In-Stream Assimilatory Nitrate Uptake from High Frequency Sensor Measurements, Environ. Sci. Technol., 50, 5685-5694, 2016a.

Rode, M., Wade, A. J., Cohen, M. J., Hensley, R. T., Bowes, M. J., Kirchner, J. W., Arhonditsis, G. B., Jordan, P., Kronvang, B., Halliday, S. J., Skeffington, R. A., Rozemeijer, J. C., Aubert, A. H., Rinke, K., and Jomaa, S.: Sensors in the Stream: The High-Frequency Wave of the Present, Environ. Sci. Technol., 50, 10297-10307, doi:10.1021/acs.est.6b02155, 2016 b.

Schaub, M., Dobbertin, M., Krauchi, N., and Dobbertin, M. K.: Preface-long-term ecosystem research: understanding the present to shape the future, Environ. Monit. Assess., 174, 1-2, 2011.

Soulsby, C., Birkel, C., and Tetzlaff, D.: Assessing urbanization impacts on catchment transit times, Geophys. Res. Lett., 41, 442448, 2014.

Sposito, G.: The chemistry of soils, 2nd ed., Oxford University Press, Oxford; New York, xii, 329 pp., 2008.

Stelzer, R. S. and Likens, G. E.: Effects of sampling frequency on estimates of dissolved silica export by streams: The role of hydrological variability and concentration-discharge relationships, Water Resour. Res., 42, W07415, doi:10.1029/2005WR004615, 2006.

Stockinger, M. P., Bogena, H. R., Lücke, A., Diekkrüger, B., Cornelissen, T., and Vereecken, H.: Tracer sampling frequency influences estimates of young water fraction and streamwater transit time distribution, J. Hydrol., 541, Part B, 952-964, doi:10.1016/j.jhydrol.2016.08.007, 2016.

Tetzlaff, D., Birkel, C., Dick, J., Geris, J., and Soulsby, C.: Storage dynamics in hydropedological units control hillslope connectivity, runoff generation, and the evolution of catchment transit time distributions, Water Resour. Res., 50, 969-985, 2014.

Timbe, E., Windhorst, D., Celleri, R., Timbe, L., Crespo, P., Frede, H.-G., Feyen, J., and Breuer, L.: Sampling frequency tradeoffs in the assessment of mean transit times of tropical montane catchment waters under semi-steady-state conditions, Hydrol. Earth Syst. Sci., 19, 1153-1168, doi:10.5194/hess-19-11532015, 2015. 
Tweed, S., Munksgaard, N., Marc, V., Rockett, N., Bass, A., Forsythe, A. J., Bird, M. I., and Leblanc, M.: Continuous monitoring of stream delta O-18 and delta H-2 and stormflow hydrograph separation using laser spectrometry in an agricultural catchment, Hydrol. Process., 30, 648-660, 10.1002/hyp.10689, 2016.

Vitvar, T. and Balderer, W.: Estimation of mean water residence times and runoff generation by $\mathrm{O}-18$ measurements in a preAlpine catchment (Rietholzbach, eastern Switzerland), Appl. Geochem., 12, 787-796, 1997.
Weiler, M., Scherrer, S., Naef, F., and Burlando, P.: Hydrograph separation of runoff components based on measuring hydraulic state variables, tracer experiments, and weighting methods, Integrated Methods in Catchment Hydrology: Tracer, Remote Sensing and New Hydrometric Techniques, 249-255, 1999.

Wels, C., Cornett, R. J., and Lazerte, B. D.: Hydrograph Separation - a Comparison of Geochemical and Isotopic Tracers, J. Hydrol., 122, 253-274, doi:10.1016/0022-1694(91)90181-G, 1991. 